\title{
Using Model-Data Fusion to Interpret Past Trends, and Quantify Uncertainties in Future Projections, of Terrestrial Ecosystem Carbon Cycling
}

\section{Citation}

Keenan, Trevor F., Eric Davidson, Antje M. Moffat, William Munger, and Andrew D. Richardson. 2012. Using model-data fusion to interpret past trends, and quantify uncertainties in future projections, of terrestrial ecosystem carbon cycling. Global Change Biology 18(8): 2555-2569.

\section{Published Version}

doi:10.1111/j.1365-2486.2012.02684.x

\section{Permanent link}

http://nrs.harvard.edu/urn-3:HUL.InstRepos:10621948

\section{Terms of Use}

This article was downloaded from Harvard University's DASH repository, and is made available under the terms and conditions applicable to Open Access Policy Articles, as set forth at http:// nrs.harvard.edu/urn-3:HUL.InstRepos:dash.current.terms-of-use\#OAP

\section{Share Your Story}

The Harvard community has made this article openly available.

Please share how this access benefits you. Submit a story.

\section{Accessibility}


Received Date : 17-Jan-2012

Accepted Date : 23-Feb-2012

Article type : Primary Research Articles

\section{Using model-data fusion to interpret past trends, and quantify uncertainties in future projections, of terrestrial ecosystem carbon cycling}

T.F. Keenan ${ }^{1}$, E. Davidson ${ }^{2}$, A. Moffat ${ }^{3}$, W. Munger ${ }^{4}$, A.D. Richardson ${ }^{1}$

${ }^{1}$ Department of Organismic and Evolutionary Biology, Harvard University, Cambridge MA, 02138 USA.

${ }^{2}$ Woods Hole Research Center, 149 Woods Hole Road, Falmouth, 02540-1644 MA, USA

${ }^{3}$ Max Planck Institute for Biogeochemistry, Hans-Knoll-Strasse, 07745 Jena, Germany

${ }^{4}$ School of Engineering and Applied Sciences and Department of Earth and Planetary

Sciences, Harvard University, Cambridge MA, 02138 USA.

Corresponding author:

T.F. Keenan

Phone: +1 (617) 496-0825

Email: tkeenan@oeb.harvard.edu

This is an Accepted Article that has been peer-reviewed and approved for publication in the Global Change Biology, but has yet to undergo copy-editing and proof correction. Please cite this article as an "Accepted Article"; doi: 10.1111/j.1365-2486.2012.02684.x 


\section{Abstract}

Uncertainties in model projections of carbon cycling in terrestrial ecosystems stem from inaccurate parameterization of incorporated processes (endogenous uncertainties) and processes or drivers that are not accounted for by the model (exogenous uncertainties). Here we assess endogenous and exogenous uncertainties using a model-data fusion framework benchmarked with an artificial neural network (ANN). We used 18 years of eddy-covariance carbon flux data from the Harvard Forest, where ecosystem carbon uptake has doubled over the measurement period, along with 15 ancillary ecological data sets relative to the carbon cycle. We test the ability of combinations of diverse data to constrain projections of a process-based carbon cycle model, both against the measured decadal trend and under future long-term climate change. The use of highfrequency eddy-covariance data alone is shown to be insufficient to constrain model projections at the annual or longer time step. Future projections of carbon cycling under climate change in particular are shown to be highly dependent on the data used to constrain the model. Endogenous uncertainties in long-term model projections of future carbon stocks and fluxes were greatly reduced by the use of aggregated flux budgets in conjunction with ancillary data sets. The data-informed model, however, poorly reproduced interannual variability in net ecosystem carbon exchange and biomass increments, and did not reproduce the long-term trend. Furthermore, we use the modeldata fusion framework, and the ANN, to show that the long-term doubling of the rate of 
carbon uptake at Harvard forest cannot be explained by meteorological drivers, and is driven by changes during the growing season. By integrating all available data with the model-data fusion framework we show that the observed trend can only be reproduced with temporal changes in model parameters. Together, the results show that exogenous uncertainty dominates uncertainty in future projections from a data-informed processbased model.

Introduction

Terrestrial ecosystems mediate a large portion of the $\mathrm{CO}_{2}$ flux between the Earth's

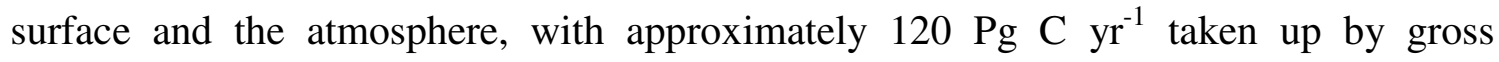
photosynthesis, and a slightly smaller amount respired back (Prentice et al., 2000; Beer et al., 2010; Pan et al., 2011). The balance of these two numbers, net ecosystem exchange, drives the terrestrial carbon cycle and is tightly coupled to the growth rate of atmospheric $\mathrm{CO}_{2}$ (Bosquet et al., 2000; Knorr et al., 2007). For policy makers, and many earth-system scientists, a major goal of global change research is therefore to understand the processes responsible for changes in terrestrial carbon cycling, and to project future states of ecosystems and climate at decadal, or even longer time scales (Clark et al., 2001; Luo et al., 2011).

Increasingly, many long-term data sets show trends that demand investigation. Inventory data show increased forest growth rates in eastern North America (McMahon et al., 2010), potentially due to recent changes in climate, nutrient deposition, or community structure. Similar increases in tropical (Lewis et al., 2009) and temperate (Salzer et al., 2009, Urbanski et al., 2007; Pilegaard et al., 2011; Dragoni et al., 2011) forest carbon uptake have been reported (but see Fahey et al., 2005), and have been linked to changes 
in the growing season length, and vegetation dynamics. Open questions remain as to the dominant controls of such long-term changes, and the relative importance of climatic and biotic factors (Richardson et al., 2007). As we move into a data-rich era in ecology (Luo et al., 2008), and an era of advanced data mining (e.g., Abromowitz et al., 2007; Moffat et al., 2010) and model uncertainty analysis techniques (e.g., Braswell et al., 2005; Wang et al., 2009; Keenan et al., 2011c) we are now in a position to address such long-term questions.

Process based models are the most commonly used tools for the projection of long-term ecosystem function. For terrestrial vegetation, the term 'process-based' incorporates a broad range of methodologies for describing eco-physiological processes, from semiempirical relationships to mechanistic descriptions based on physical laws. Such models are often shown to reproduce observations 'reasonably well' (e.g., Williams et al., 2005; Braswell et al., 2005). However, model intercomparisons and model-data comparison studies show tremendous variations among models for both short- and long-term projections (e.g., Friedlingstein et al., 2006; Siqueira et al. 2006; Sitch et al., 2008; Schwalm et al., 2010; Dietze et al., 2012; Keenan et al., in pressGCB).

Model-data fusion (also referred to as 'data assimilation', or 'inverse modeling') (Wang et al., 2009; Keenan et al., 2011c) is a means by which to use observational data to optimize a model and quantify model uncertainty. The approach identifies combinations of model parameters that give an equivalent model-data agreement. In this way, data from different sources can be synthesized using the model as the interpreter, independent of parameter assumptions. Results are conditional on model structure, and the information content of observational data along with data uncertainties (Raupach et 
al., 2005; Keenan et al., 2011c). For example, model-data fusion applications of both simple (Braswell et al., 2005) and complex (Medvigy et al., 2009) models at Harvard forest acknowledged the limitation of using only one or two data streams to constrain model parameterization.

Even with an optimized model, results remain contingent on model structure. An optimized model is therefore not necessarily correct, or even good. For example, if the model structure is inadequate, or the model parameters are not well constrained, an optimized model can get the right answer for the wrong reason or through a variety of unverified process combinations (equifinality) (Beven, 2006). It is thus important to test the optimized model against data that was not used for training. Another approach to assessing model performance is to test the optimized model using an independent 'benchmark'. Empirical data-mining tools such as artificial neural networks can serve as an excellent means by which to benchmark model performance (Abramowitz, 2007). Such data-mining tools have been shown to capture the complex response of ecosystem carbon cycling to climatic drivers (Moffat et al., 2010). They therefore provide an indication of how well a good (though not necessarily best) model should be expected to perform.

Carbon uptake at Harvard forest has increased from $\sim 200$ to $\sim 500 \mathrm{~g} \mathrm{C} \mathrm{m}^{-2} \mathrm{y}^{-1}$ during the 18-year period from 1992 to 2009; around this long-term trend, there is also interannual variability on the order of $\pm 117 \mathrm{~g} \mathrm{C} \mathrm{m}^{-2} \mathrm{y}^{-1}$ (1 SD). In this paper, we use a parsimonious forest carbon cycle model, embedded in a multiple constraints Markov chain Monte Carlo optimization framework, to examine trends and variability in uptake. We first 
assess the impact of using different data constraints on uncertainty in model performance, both in training and test periods. An artificial neural network approach (Moffat et al., 2010) is then used to benchmark the optimized process-based model. By examining how the use of different constraints can reduce uncertainty we test whether recent changes in uptake are driven by concurrent trends external to the model system (exogenous factors) or model-internal (endogenous) factors. The impact of endogenous uncertainty in ecological forecasting is also assessed and compared to current trends in carbon uptake at the Harvard forest.

\section{Materials and Methods}

\section{Site}

All data used were obtained within the footprint of the eddy-covariance tower at the Harvard Forest Environmental Measurement Site (HFEMS) (http://atmos.seas.harvard.edu/lab/hf/index.html), which is located in the New England region of the northeastern United States $(42.53 \mathrm{~N} 72.17 \mathrm{~W}$, elevation $340 \mathrm{~m})$ (Wofsy et al., 1993; Barford et al., 2001; Urbanski et al., 2007). The forest within the tower footprint is largely deciduous, dominated by red oak (Quercus rubra, 52\% basal area), red maple (Acer rubrum, 22\% basal area), eastern hemlock (Tsuga Canadensis, 17\% basal area), and a secondary presence of white pine (Pinus strobus) and red pine (Pinus resinosa) are also found within the tower footprint.

\section{Data}

We used 18 complete years (1992-2009) of hourly meteorological and eddy-covariance (Wofsy et al., 1993; Goulden et al., 1996; Barford et al., 2001; Urbanski et al., 2007) $\begin{array}{llll}\text { measurements } & \text { of } & \text { ecosystem } & \end{array}$ 
(http://atmos.seas.harvard.edu/lab/data/nigec-data.html). Hourly gap-filled meteorological variables used include incident photosynthetically active radiation (PAR), air temperature above the canopy, soil temperature at a depth of $5 \mathrm{~cm}$, vapor pressure deficit, and atmospheric $\mathrm{CO}_{2}$ concentration. Quality controlled hourly eddycovariance observations (without gap-filling) of NEE were used to optimize the ecosystem model and train the artificial neural network. Gap-filled NEE values were only used to provide annual sums for evaluating optimized model performance.

For ancillary data constraints we used measurements of leaf area index, soil organic carbon content, carbon in roots, carbon in wood, wood carbon annual increment, observer-based estimates of bud-burst and leaf senescence, leaf litter, woody litter, and continuous and manual measurements of soil respiration (Table 1), downloaded from the Harvard forest data repository (http://harvardforest.fas.harvard.edu/data/archive.html).

In addition to the ancillary data available from the Harvard forest data repository, we used two other model constraints: 1) annual estimates of the contribution of root respiration to total soil respiration, and 2) estimates of turnover times of soil organic matter pools. Radiocarbon and soda-lime (in combination with trenching) based estimates of the contribution of autotrophic respiration ( $\mathrm{Ra}$ ) to total soil respiration (Rsoil) were obtained from Gaudinski et al. (2000), Bowden et al. (1993) and Davidson (unpublished data). Bowden et al. (1993) provide a mean annual estimate of belowground autotrophic respiration as roughly $33 \%$ of total annual soil respiration. Gaudinski et al. (2000) and unpublished data from Davidson et al. suggested an 
approximate error of roughly $50 \%$ associated with this estimate. Although annual fluxes were constrained to a specific proportion, Ra:Rsoil could vary on shorter timescales. Turnover times of litter and the two soil organic matter pools (slow, passive) were also taken from Gaudinski et al. (2000). Microbial biomass turnover times were estimated as $1.7+/-1.3$ years (Davidson et al. unpublished data).

Estimates of uncertainty were used for each data stream in the optimization. Uncertainty estimates for NEE were taken from Richardson et al. (2006), where uncertainties were shown to follow a double-exponential distribution, with the standard deviation of the distribution specified as a linear function of the flux. Estimates of uncertainty due to flux gap-filling (which apply to the annual NEE totals) were taken from Barr et al. (in review). Soil respiration uncertainty estimates were taken from Savage et al. (2009) and Phillips et al., (2010), where measurement uncertainty increased linearly with the magnitude of the flux. Leaf area index (LAI) sampling uncertainties were estimated as the standard error $(n=34$ plots) of the mean LAI. Litterfall sampling errors were calculated as the standard error $(n=34$ plots $)$ of the annual total litterfall across all plots. Uncertainty of carbon in wood was calculated from the standard error ( $n=34$ plots, 635 trees) of the mean plot-level cumulative increment, which averaged $\sim 10 \%$ over all years. Two independent measurements (Gaudinski et al., 2000; Bowden et al., 2009) were used to constrain the initial value of total soil $\mathrm{C}$ content $\left(\mathrm{C}_{\mathrm{SOM}}=8.3 \pm 1.4 \mathrm{~kg} \mathrm{C} \mathrm{m}^{-2}\right.$; mean \pm 1 SE), with uncertainties estimated based on the standard deviation between datasets. Root biomass uncertainties were estimated from spatial variation in the samples $(n=21$ plots $)$, taken in the control plots of the DIRT project 
(http://www.lsa.umich.edu/eeb/labs/knute/DIRT/). Uncertainty estimates for the dating of phenological events were based on the between tree standard deviation.

Additionally, three different soil respiration data sets, two automated and one manual, were used (Savage et al., 2009; Phillips et al., 2010). Although seasonal cycles were similar between the data sets, disagreement in the magnitude of the flux was evident between the different soil respiration data sets, reflecting high spatial variability in soil characteristics. We included three additional scaling parameters (data harmonizing parameters) in the optimization process (e.g., van Oijen et al., 2011). These scale different chamber datasets to account for the possibility that a particular dataset is not representative of the mean soil respiration of the tower footprint. This thus harmonizes the magnitude of the different soil respiration data streams to give an estimate of the spatial average soil respiration of the tower footprint, but then leverages the temporal patterns in the data as model constraints.

\section{The FöBAAR Model}

We developed a forest carbon cycle model that strikes a balance between parsimony and detailed process representation. Working on an hourly timescale, FöBAAR (Forest Biomass, Assimilation, Allocation and Respiration) calculates photosynthesis from two canopy layers, and respiration from eight carbon pools (leaf, wood, roots, soil organic matter [microbial, slow and passive pools], leaf litter and [during phenological events] mobile stored carbon), using as environmental forcings canopy air temperature (Ta), 5 
$\mathrm{cm}$ soil temperature (Ts), photosynthetic active radiation (PAR), vapour pressure deficit (VPD), and atmospheric $\mathrm{CO}_{2}$.

The canopy in FöBAAR is described in two compartments representing sunlit and shaded leaves (Sinclair et al., 1976; Wang \& Leuning, 1998). Intercepted radiation by sunlit or shade leaves depends on the position of the sun, and the area of leaf exposed to the sun based on leaf angle and the canopy's ellipsoidal leaf distribution (Campbell, 1986). Here we assume a spherical leaf angle distribution. Assimilation rates for sunlit and shaded leaves are calculated through the commonly used Farquhar approach (Farquhar et al., 1980; De Pury \& Farquhar, 1997), with dependencies on absorbed direct and diffuse radiation, air temperature, VPD and the concentration of $\mathrm{CO}_{2}$ within the leaf inter-cellular spaces. Stomatal conductance is calculated using the Ball-Berry model (Ball et al., 1987), coupled to photosynthetic rates through the analytical solution of the Farquhar, Ball Berry coupling (Baldocchi, 1994). Rates of photosynthesis are dependent on the minimum between rate of carboxylation and the proportional rate of electron transport. The canopy integrated (over space and time) RuBP (ribulose-1,5bisphosphate) rate of carboxylation, $V_{c}$, and the rate of electron transport, $J$, are calculated following Farquhar et al. (1980) and de Pury and Farquhar (1997). The $\mathrm{CO}_{2}$ compensation point and the mitochondrial respiration rate are calculated using an Arrhenius-type equation (Bernacchi et al., 2002).

Maintenance respiration is calculated as a fraction of assimilated carbon. The remaining assimilate is allocated to foliar carbon, then to the wood and root carbon pools on a daily 
time step. Mobile stored carbon relates only to foliage, and is respired only during periods of bud-burst and leaf-fall. Carbon allocation and canopy phenology are simulated as in the DALEC model (Williams et al., 2005; Fox et al., 2009).

Root respiration is calculated hourly and coupled to photosynthesis through the direct allocation to roots. Dynamics of soil organic matter is modeled using a three-pool approach (microbial, slow, and passive pools) (Knorr et al., 2005). Decomposition in each pool is calculated hourly, with a pool specific temperature dependency. Litter decomposition is also calculated hourly, but on an air temperature basis. Litter and root carbon are transferred to the microbial pool, then to the slow and finally to the passive pool.

In total, 35 model parameters (including three data harmonization parameters, Table 2; P40, P41, P42) and 7 initial pools were optimized, giving a total of 42 free parameters. The inclusion of the initial biomass and soil pools in the optimization process removed the need for a model spin-up.

\section{Model-data fusion}

An adaptive multiple constraints Markov-chain Monte Carlo $\left(\mathrm{MC}_{3}\right)$ optimization was used to optimize the process-based model and explore model uncertainty. The algorithm uses the Metropolis-Hastings (M-H) approach (Metropolis and Ulam, 1949; Metropolis et al., 1953; Hastings, 1970) combined with simulated annealing (Press et al., 1992). It is loosely based on that of Braswell et al. (2005), and is adaptive in the sense that the step 
size, which is expressed as a fraction of the initial parameter range, is automatically adjusted in order to obtain a fixed acceptance rate. Preliminary tests with synthetic data indicated an acceptance rate of $\sim 21 \%$ gave optimal efficiency (good mixing) for the posterior exploration. Prior distributions for each parameter given in Table 2 were assumed to be uniform (non-informative, in a Bayesian context).

The optimization process uses a two-step approach. In the first stage, the parameter space is explored for 100,000 iterations using the $\mathrm{MC}_{3}$ optimization algorithm. At each iteration the current step size is used as the standard deviation of random draws from a normal distribution with mean zero, by which parameters are varied around the previous accepted parameter set. Parameters that fall outside the initial parameter range are 'bounced' back within their range. This stage identifies the optimum parameter set by minimizing the cost function (see Eq. 2 below). 100,000 model iterations were used to identify the optimum parameter set, as longer runs led to no improvement.

In the second stage, the parameter space is again explored, and a parameter set is accepted if the cost function for each data stream (defined below) passes a $\chi^{2}$ test (at 90\% confidence) for acceptance/rejection (after variance normalization based on the minimum cost function obtained (e.g. Franks et al., 1999; Richardson et al., 2010)). This approach is preferable to using the aggregate cost function, as it ensures that model predictions are consistent with each of the individual data streams. 
The cost function quantifies the extent of model-data mismatch using all available data (eddy-covariance, biometric, etc.), constructed here as in Keenan et al. (2011c). Individual data stream cost functions, $j_{i}$, are calculated as the total uncertainty-weighted squared data-model mismatch, averaged by the number of observations for each data stream $\left(N_{i}\right)$ :

$$
j_{i}=\left(\sum_{t=1}^{N_{i}}\left(\frac{y_{i}(t)-p_{i}(t)}{\delta_{i}(t)}\right)^{2}\right) / N_{i}
$$

where $y_{i}(t)$ is a data constraint at time $t$ for data stream $i$ and $p_{i}(t)$ is the corresponding model predicted value. $\delta_{i}(t)$ is the measurement specific uncertainty. For the aggregate multi-objective cost function we use the average of the individual cost functions, which can be written as:

$$
J=\left(\sum_{i=1}^{M} j_{i}\right) / M
$$

where $M$ is the number of data streams used.

Thus, each individual cost function is averaged by the number of observations and the average of the cost functions from all data streams is taken as the total cost function. In this manner each data stream is given equal importance in the optimization (Franks et al., 1999; Barrett et al., 2005).

\section{Model Benchmarking - Artificial Neural Network Ensemble}

We used an Artificial Neural Network (ANN) to benchmark the FöBAAR model performance (e.g., Abramowitz et al., 2007) and characterize the climatic sensitivity of ecosystem-atmosphere carbon exchange. An ANN is an inductive modeling approach 
based on statistical multivariate modeling (Bishop, 1995; Rojas, 1996) by which one can map drivers directly onto observations (e.g., Moffat et al., 2010). The benchmarking framework used in this paper is based on a feed-forward ANN with a sigmoid activation function trained with a back propagation algorithm (Moffat et al., 2010; Moffat et al., 2012). An ensemble of six ANNs was trained on non gap-filled eddy-covariance carbon fluxes only. It should be noted that the ANN is a benchmark only for short-term environmental controls on hourly NEE, as it does not account for lagged effects on ecosystem state or function, or long term changes in pool sizes.

The ANN was also used as a gap-filling tool to compare to the gap-filled eddycovariance carbon fluxes. When used as a gap-filling tool (e.g. Moffat et al. 2008), the ANN was trained on each year of eddy-covariance carbon flux data separately. Thus applied, the ANN agreed with the annual carbon flux from the independently gap-filled data with a root mean square error of $32 \mathrm{~g} \mathrm{C} \mathrm{m}^{-2}$.

\section{Experimental Set-up}

We divided the 18 years of available data into three distinct 6-year periods (1992-1997; 1998-2003; 2004-2009. Fig. 2) to perform two experiments. In the first experiment, we used the middle period (Period 2, Fig. 1) to quantify the added benefit of using different data streams as constraints. This involved optimizing FöBAAR using as constraints either: 1) only hourly net ecosystem exchange data; 2 ) hourly, monthly and yearly net ecosystem exchange data, or (3) all eddy-covariance carbon flux data (hourly, monthly, yearly) and ancillary data (Table 1). We then assessed the optimized model performance 
for the two periods not used for training. The ANN was trained to the eddy-covariance carbon flux data for the same 6-year period on which the FöBAAR model was trained and compared to the FöBAAR model.

The second experiment was designed to test whether model deficiencies highlighted by the first experiment could be resolved by training the model on each period. In the second experiment, we used all available data to optimize the FöBAAR model on each 6-year period individually. This allowed us to assess changes in model parameters when optimized on different periods.

Finally, for each of the three approaches to constraining the model (1,2 and 3 above) in the first experiment, we projected carbon stocks and fluxes to 2100 , in order to assess the effect of each constraint approach on the future propagation of uncertainty.

\section{Downscaled future climate projections}

For the climate change projection, we used downscaled data (Hayhoe et al., 2008) from the regionalized projection of the GFDL-CM global coupled climate-land model (Delworth et al., 2006) driven with socio-economic change scenario A1FI (IPCC, 2007). Model projections for Harvard forest under this scenario predict an increase in atmospheric $\mathrm{CO}_{2}$ to 969 ppm by 2100, and an increase in mean annual temperature from 7.1 to $11.9{ }^{\circ} \mathrm{C}$. 


\section{Results}

\section{Assessing the benefit of additional constraints}

We first tested the benefit of using flux and ancillary data for constraining model projections. Here we use the middle six years of the time series (Period 2, Fig. 2) to optimize the FöBAAR model and the other two periods for testing, assessing three different approaches to constraining the model (see Methods section). When using only hourly net ecosystem exchange as a constraint, uncertainty in annual mean net ecosystem exchange model estimates was large (+/- $200 \mathrm{gC} \mathrm{m}^{-2} \mathrm{yr}^{-1} 95 \%$ CI, Fig. 1). Particularly large uncertainty was evident among the component fluxes of gross primary productivity (+/- $\left.320 \mathrm{gC} \mathrm{m}^{-2} \mathrm{yr}^{-1}\right)$, autotrophic (+/- $\left.410 \mathrm{gC} \mathrm{m}^{-2} \mathrm{yr}^{-1}\right)$ and heterotrophic

respiration (+/- $\left.290 \mathrm{gC} \mathrm{m}^{-2} \mathrm{yr}^{-1}\right)$. The use of monthly and annual flux aggregates largely reduced uncertainty in model estimates of annual net ecosystem exchange (to +/- $60 \mathrm{gC}$ $\mathrm{m}^{-2} \mathrm{yr}^{-1}$ ) during both the training and test periods, though only slightly reduced equifinality, shown in Fig. 1 as relatively large uncertainties in the component fluxes. Using all available data to constrain the model only slightly reduced uncertainty for annual flux estimates but gave a large reduction in uncertainty in the responsible processes (Fig. 1). Uncertainty in modeled fluxes in the test periods was comparable to that in the training period for each of the constraint approaches.

\section{FöBAAR and ANN evaluation in training and test periods}

In the following analysis, we trained both FöBAAR using all constraints and the ANN on Period 2 using only short term flux constraints (Fig. 2), and tested the models on the 
other two periods. When trained on Period 2, neither FöBAAR nor the ANN captured the large increase in annual NEE during Period 3 (Fig. 3). The mean annual NEE estimated from the gap-filled tower data for the last six years of the time series (Period 3, Fig. 2) was roughly twice that of the previous six-year period (Period 2, Fig. 2). In contrast, both FöBAAR and the ANN mean annual NEE for Period 3 was comparable to that of Period 2 (Fig. 2). As with all models that do not consider dynamic vegetation, FöBAAR and ANN predictions of NEE outside the training period make the implicit assumption that the climatic sensitivity of ecosystem function does not change between years. Long-term temporal trends in the residuals between the modeled and observed annual NEE can be interpreted as an alteration in the carbon uptake of the ecosystem that is independent of recent changes in the climate variables included in the model. Long-term trends in Harvard Forest mean annual uptake (increased by $\sim 300 \mathrm{gC} \mathrm{m}{ }^{-2}$ ( 150\%) between Period 1 and Period 3) were thus shown to be independent of any recent changes in climate drivers included here.

In general, when trained on Period 2, the FöBAAR model reproduced the mean values for the ancillary data streams, but not the interannual variability. FöBAAR-modeled

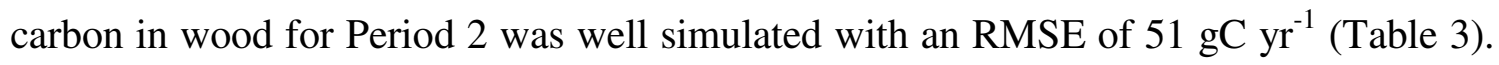
Mean annual wood increments were also well captured, allowing for the accurate reproduction of biomass accumulation. Outside of the training period, RMSE performance for woody biomass was reduced, most noticeably for mean annual woody increment in Period 3, where the model under-predicted growth. Interannual variability in modeled wood increment did not show a significant correlation with the observations 
in any period (Table 3). For canopy processes, the seasonal evolution of leaf area index (LAI) was well captured during the training period $\left(\mathrm{r}^{2}: 0.89\right.$, RMSE: $\left.0.49 \mathrm{~m}^{2} \mathrm{~m}^{-2}\right)$. Mean bud-burst dates were well simulated (RMSE: 4.17 days), though interannual variability was not $\left(r^{2}: 0.24\right)$. Mean leaf senescence was simulated with a similar accuracy (RMSE: 3.4 days) though model correlation with inter-annual variability in senescence was low $\left(r^{2}: 0.35\right)$. Outside of the training period, model skill at reproducing observations of LAI, and phenology declined (Table 3), most notably in Period 3, and in particular for interannual variability in leaf senescence. The magnitude of leaf litterfall was well simulated for the training period (RMSE: $12 \mathrm{gC} \mathrm{m}^{-2}$ ) but much less so for Period 3 (RMSE: $51 \mathrm{gC}$ $\mathrm{m}^{-2}$ ), and interannual variability was poorly captured in all three periods.

For hourly daytime net ecosystem exchange in the training period, FöBAAR and the ANN performed comparably $\left(\mathrm{r}^{2}: 0.76,0.74\right)$, with an equivalent RMSE (0.19). The ANN showed better data-model agreement for the night-time fluxes than the FöBAAR model (Table 3). Cumulative annual fluxes show that both models tended to slightly underestimate the total annual NEE. Neither the FöBAAR model nor the ANN captured the high uptake seen in 2001 (data not shown), suggesting that the observed uptake in this year was not driven by the climatic variables included in this study. The ANN residuals showed no seasonal bias during the training period, whereas the optimized FöBAAR was slightly biased towards underestimating uptake during the growing period, and underestimating carbon released by the ecosystem during winter months (Fig. 3). 
For the testing periods, both the ANN and the FöBAAR model performed well for hourly NEE fluxes during 1992-1997 (Period 1, Fig. 3), with no systematic temporal biases (Fig. 3). During 2004-2009, FöBAAR and the ANN both showed strong systematic biases, but only during the growing season (Fig. 3) in particular during the months of June, July, August and September (Fig. 3, panel C). The correlation of measured and ANN/FöBAAR-modeled day-time NEE for the 2004-2009 period was equivalent to that of the other two periods, but a larger bias was evident for hourly predictions which accumulated to a large bias in the annual total (Table 3). This shows that good correlation to short term fluxes does not eliminate the possibility of large bias at longer time scales.

\section{Model extrapolation in time}

With a perfect understanding of the system, a model trained on one period should be able to predict the fluxes in the other periods. Experiment 1 showed that neither model used here could do so at Harvard Forest. In experiment 2 we calibrated the FöBAAR model to each period individually. When calibrating FöBAAR to all of the available data on the three individual periods, little bias is evident for FöBAAR NEE during that period, but large biases are evident in the other periods (Fig. 4). Calibrating to the whole time series thus over-estimates annual NEE for the first period, gives low bias in annual NEE for the middle period, and under-estimates annual NEE for the last period. Interannual variability in NEE was not captured by the model when trained on any period. Long-term changes in estimated modeled canopy photosynthetic potential (here $V c_{\max }$, P19) were needed in order to reproduce the observations. Reproducing the required 
trend in NEE required an increase in $V c_{\max }$ of $\sim 50 \%$ over the 18 years (Fig. 5). $V c_{\max }$ covaried strongly with the proportion of assimilate lost through maintenance respiration (Fig. 5). Such parameter equifinality could explain previous findings that models with very different $V c_{\max }$ values can give comparable estimates of canopy photosynthesis (e.g., Keenan et al., 2011b). Although the use of multiple constraints allowed for the constraining of 24 of the 42 free model parameters, no other significant changes in parameters could be detected between the different periods.

\section{Long-term changes at Harvard Forest}

From a carbon accounting perspective, changes in the measured annual increment in aboveground biomass over the 18 years (Period 1: 100 gC m-2; Period 2: $185 \mathrm{gC} \mathrm{m}^{-2}$;

Period 3: $220 \mathrm{gC} \mathrm{m}^{-2}$ ), do not fully account for the observed increase in ecosystem carbon storage (NEE). In Period 2, measured aboveground biomass increment was 72\% of all carbon sequestered. In Period 3, biomass increment accounted for $42 \%$ of observed carbon sequestered. In our model system, which accurately reproduced the mean biomass increment for each period, the remaining increase in uptake could only accumulate in the litter, root or soil pools. In the model, any increase in the root, litter, or microbial pools would cause an observable increase in soil respiration, yet no increase in soil respiration was observed between the different periods. As the only viable alternative, the model predicted that the remaining uptake (after discounting for increases in aboveground biomass) accumulated in the slow cycling carbon pool at a rate of $300 \mathrm{gC} \mathrm{m}^{-2} \mathrm{yr}^{-1}$ during Period 3. This contrasted with the accumulation rate of $\sim 70 \mathrm{gC}$ 
$\mathrm{m}^{-2} \mathrm{yr}^{-1}$ in periods 1 and 2 . This implies that the reported large increase in net ecosystem carbon uptake, if true, should be detectable in the slow cycling carbon pool.

\section{Ecological forecasting}

Long-term model projections of future carbon cycling and stocks (using posterior parameter distributions from the FöBAAR model optimized on Period 2) were strongly dependent on the data used to constrain the model (Fig. 6). The use of short-term (hourly) NEE flux data alone, although it gave a good fit to available hourly NEE measurements (Table 3), led to poor constraint of the long-term evolution of the carbon sink-source state of the forest. Future projections of annual NEE were highly uncertain and ranged from $\sim 600$ to $-900 \mathrm{gC} \mathrm{m}^{-2} \mathrm{y}^{-1}$ (90\%C.I.) in the last decade of the century, compared with an average range of -50 to $-520 \mathrm{gC} \mathrm{m}^{-2} \mathrm{y}^{-1}$ (90\%C.I.) in present day conditions (when using only hourly NEE flux data). Largest uncertainty propagated beyond 2050. Uncertainty in autotrophic respiration increased by $\sim 50 \%$ by the end of the century and uncertainty in heterotrophic respiration doubled.

The use of long-term (monthly and annual) flux constraints greatly reduced future flux uncertainty. For example uncertainty in future NEE was reduced to within a range of -50 to $-450 \mathrm{gC} \mathrm{m}^{-2} \mathrm{y}^{-1}$. The largest reduction in uncertainty came from the synchronous use of all data constraints available. The additional use of biometric constraints particularly reduced endogenous uncertainty in future projections of all carbon stocks. With the use of all data constraints, uncertainty in projections of all future stocks and fluxes was within present day uncertainty, with the exception of the slow cycling carbon pools (soil 
organic matter and carbon in wood). Interestingly, projected future carbon sequestration under climate change is never predicted to increase to the extent observed in the last 18 years at Harvard forest.

Discussion

High frequency eddy-covariance measurements of forest-atmosphere carbon exchange contain a wealth of information, which can be used to characterize an ecosystems response to climatic drivers, and the evolution of that response over time. When used to constrain a terrestrial carbon cycle model, a large improvement in posterior vs prior model performance can be achieved for high frequency fluxes (e.g., Medvigy et al., 2009), along with a reduction in the posterior uncertainty of some model parameters (e.g. Braswell et al., 2005). The annual carbon balance of an ecosystem, however, is not an instantaneous response to a driver, but an accumulation of ecosystem responses to climate variability within the year (leMaire et al., 2007). Here we show that when using only high frequency measurements of net ecosystem exchange, small high-frequency model biases can accumulate to give large uncertainty in the total modeled annual carbon balance of the ecosystem over annual and inter-annual time periods. The resulting uncertainty range is of a similar magnitude to the range among models reported from model inter-comparison studies (Heimann et al., 1998; Cramer et al., 2001, Schwalm et al., 2010; Keenan et al., in pressGCB). By incorporating information on long-term (monthly, annual) cumulative fluxes into the model optimization, we greatly reduced the uncertainty in model estimates of the annual carbon budget of the forest in both training and test periods. 
This reduction was not as pronounced, however, for the components of the carbon budget. When using only eddy-covariance carbon flux data, modeled gross primary productivity and ecosystem respiration compensated for each other to give the observed value for net ecosystem exchange. Such equifinality (Beven, 2006) between quantities allows for large uncertainty in both, but good model performance for the net value of ecosystem carbon exchange. The use of additional constraints in conjunction with eddycovariance carbon flux data led to a reduction in uncertainty in the component parts of net ecosystem exchange during the test and training periods, if not in net ecosystem exchange itself. In particular, the additional use of biometric and soil flux constraints led to a halving of uncertainty in heterotrophic respiration, and a large reduction in uncertainty regarding the size of the carbon pools.

Synchronously using 15 different data streams as constraints successfully reduced posterior uncertainty in 24 out of 42 parameters. The well-constrained nature of the model was evidenced by the accurate simulation of multiple compartments of the ecosystem at various different time scales. Previous model-data fusion efforts have focused on using one or two constraints (with some notable exceptions e.g., Xu et al., 2006; Richardson et al., 2010; Medvigy et al., 2009; Weng \& Luo, 2011; Riccuito et al., 2011), which invariably led to a low number of constrainable parameters (e.g., $~ 4->6$ parameters, Wang et al., 2001, 2007; Knorr \& Kattge, 2005). Here, constrained parameters were typically associated with processes for which data was available. For instance, the soil organic matter and wood carbon initial pools were well constrained by 
the measurement data, whilst the canopy carbon reserve pool was not constrained, as no measurements of mobile canopy carbon were included. Five additional parameters, which were not well constrained, demonstrated strong co-variance with other parameters, thus giving information as to their true distribution. $V c_{\max }$ and the proportion of recent assimilate used for maintenance respiration serve as a good example in this study - where higher $V c_{\max }$ was compensated for by higher maintenance respiration (Fig. 5). It should be noted that the absolute values of $\mathrm{Vc}_{\max }$ reported here are specific to the model used. Different assumptions regarding the distribution of light and temperature within the canopy affect the value of $\mathrm{Vc}_{\max }$ needed to reproduce the observed fluxes (e.g., Keenan et al., 2011b), potentially along with the value assumed for the proportion of assimilate lost to maintenance respiration as shown here. The increased use of multiple data streams in the future will help better constrain models and aid our understanding of long-term processes. However, not all additional data constraints give the same reduction in model uncertainty (Richardson et al., 2010; Riccuito et al., 2011). In this study, components of ecosystem carbon cycling most uncertain after the integration of all available data were related to gross primary productivity, and the timing and magnitude of aboveground growth and maintenance respiration. Identifying which additional data would better inform model projections should be a focus of future efforts.

By testing the optimized process based model against the artificial neural network, we have shown that process-based models can reproduce observed net ecosystem exchange measurements as well as data-mining tools. This shows that parsimonious model 
structures are sufficient to reproduce the observed short-term variability represented in eddy-covariance carbon flux data. It also suggests that, although eddy-covariance fluxes undoubtedly contain more information than any other individual data constraint, they are not sufficient to adequately test many aspects of more complex models (e.g., Medvigy et al., 2009; Zaehle \& Friend, 2010; Bonan et al., 2011). As in other studies (e.g., Hanson et al., 2004; Braswell et al., 2005; Siqueira et al. 2006; Richardson et al., 2007; Urbanski et al. 2007; Richardson et al., 2010; Keenan et al., in pressGCB; but see Desai et al., 2010), the process-based model failed to accurately reproduce observed inter-annual variability in carbon cycling and biomass increments, even within the training period. As the process-based model here was optimized to the data, parameter error can be discounted, leaving model structural error, biotic effects, or missing drivers (e.g., diffuse radiation: Moffat et al., 2010) as potential culprits for the poor model performance for inter-annual variability. Lagged effects of climate variability on ecosystem state (e.g., Gough et al., 2009) have been shown to affect model performance on interannual timescales (Keenan et al., in pressGCB), potentially due to inaccurate model allocation structures (Gough et al., 2009). Though it has been suggested that process-based models may effectively reproduce inter-annual variability (Desai, 2010; but see Keenan et al., in pressGCB), both biotic and abiotic factors are known to affect normal between-year variability (Richardson et al., 2007). Further work on model structural error, biotic effects, and the impact of unaccounted for drivers should improve our ability to accurately model interannual variability in terrestrial carbon cycling in the future. 
Eddy-covariance measurements at Harvard Forest suggest a long-term trend of increasing uptake over the 1992-2009 period, with a particularly pronounced increase in uptake in the last 6 years. Results here suggest that long-term changes evidenced by the eddy-covariance carbon flux data are independent of recent changes in climate variables included in this study. By comparing the temporal distribution of model-data residuals, we found that non-climate driven change in carbon fluxes is only evident during the growing season. By comparing the posterior parameters for the FöBAAR model optimized on three separate six-year periods of contrasting uptake, we show that even with increased leaf area, substantial increases in canopy productivity (here $\mathrm{Vc}_{\max }$ ) are needed in order to reproduce the observed fluxes.

Although carbon in wood, leaf area and litter-fall all exhibit increases over the past 18 years, a large proportion of the estimated increased uptake is unaccounted for in the measured carbon stocks. Our model results suggest that the rate of accumulation of slow cycling soil organic matter doubled in Period 3 compared with the two earlier periods. Under that working hypothesis, the large influx of carbon in recent years should therefore be detectable with an appropriate sampling intensity (Fernandez et al., 1993) in soil organic matter measurements, with largest increases in the slow cycling soil carbon pool. Without adequate measurements, our model results regarding the fate of the sequestered carbon should not be regarded as strong evidence, and provide but a testable hypothesis. Current efforts to quantify age and residence times of soil carbon with techniques such as isotopic analysis and radiocarbon dating should aid in identifying the ultimate fate of the sequestered carbon. 
Inventory data reports an increase in the biomass of Red Oak within the tower footprint ( 20\% increase over the last 18 years), and a concurrent increase in Red Oak leaf area. Other species in the footprint of the tower do not show a comparable increase, with the exception of a slight increase in understory Hemlock. Changes in community dynamics provide one potential explanation of the changes in ecosystem uptake. Increasing understory activity has been suggested to have the potential to explain trends (Jolly et al., 2004), through enhanced photosynthetic uptake before the overstory canopy has developed in spring, or after it has senesced in autumn. Understory activity, however, is unlikely to explain the consistent higher uptake throughout the season as observed here. The observed increase in forest carbon uptake could also be due to higher atmospheric $\mathrm{CO}_{2}$ levels (Cramer et al., 2001), or the cumulative effect of nitrogen deposition. The Farquhar et al. (1980) photosynthesis model used in this study accounts for effects of increased atmospheric carbon, though there is significant uncertainty as to the direct effect of carbon fertilization (e.g., Long et al., 2006). Although nitrogen deposition at Harvard forest is 10 to 20 times above historic background levels (http://www.chronicn.unh.edu/), it remains only $\sim 12 \%$ of annual $\mathrm{N}$ mineralization (Munger et al., 1998), and control data from long-term nitrogen fertilization studies do not report a significant increase in foliar nitrogen (data not shown). It should be noted that there is no evidence to suggest that any of the processes discussed above could, in isolation, realistically lead to a $\sim 50 \%$ increase in the photosynthetic potential of the canopy. 
Future projections from terrestrial models have been reported to diverge greatly under climate change (Friedlingstein et al., 2006; Heimann \& Reichstein, 2008). Such divergence could be explained by process mis-parameterization, or mis-specification. We show that using short-term high frequency eddy-covariance carbon flux data alone to inform model parameterization allows for divergent future projections, even with good model performance when tested against current data. Parameter mis-specification could therefore potentially explain the different future trajectories reported by different models. We show that using orthogonal constraints can reduce this divergence, leading to a better data-informed model projection. Using long-term flux data in combination with biometric data greatly reduced endogenous (internal to the model system) uncertainty in predictions of how net carbon sequestration at Harvard Forest would respond to future climate change. Considerable uncertainty in the components of net ecosystem exchange remained, due to equifinality between gross photosynthesis and autotrophic respiration.

Although process-based models should theoretically be more reliable than empirical models under future climate scenarios (see Keenan et al., 2011a for discussion), not all processes are fully understood (e.g., species adaptation, down-regulation, nitrogen cycling etc.). Such exogenous uncertainty is shown here to be large, with the optimized model incapable of reproducing the observed long-term trend in carbon cycling at Harvard forest without temporal changes in parameters. This suggests that, when the model is sufficiently informed by data, model process representation still represents a 
large source of uncertainty for making future projections, making the statistical uncertainty in ecological forecasts an underestimate of the true uncertainty.

Models of forest carbon cycling, such as the one used here, have been coupled with earth system models to project terrestrial carbon sinks and sources (e.g., Sitch et al., 2008) and feedbacks to climate change in the 21st century (Cox et al., 2000; Fung et al., 2005; Friedlingstein et al., 2006). Results have been incorporated into the assessment reports of the Intergovernmental Panel on Climate Change (IPCC, 2007) to guide mitigation efforts by governments and public (Solomon et al., 2007), though models diverge largely when projecting the future responses to climate change (Friedlingstein et al., 2006; IPCC, 2007). None of the terrestrial carbon cycle models used, however, are directly informed by data. Here we have shown how this can lead to overconfidence in individual model projections. Model intercomparison studies that use data-informed models would be a significant step towards rigorously assessing errors due to model process representation, and improving our ability to provide policy-actionable predictions of future carbon cycle responses to change. 


\section{Acknowledgments}

Carbon flux and biometric measurements at HFEMS have been supported by the Office of Science (BER), U.S. Department of Energy (DOE) and the National Science Foundation Long-Term Ecological Research Programs. TFK and ADR acknowledge support from the Northeastern States Research Cooperative, and from the U.S. DOE BER, through the Northeastern Regional Center of the National Institute for Climate Change Research. TFK, ADR, and JWM acknowledge support from NOAA's Climate Program Office, Global Carbon Cycle Program, under award NA11OAR4310054. We thank Y. Ryu, M. Toomey and S. Klosterman for useful feedback. We especially thank the many participants who have sustained the long-term data collection, and in particular the summer students engaged in collecting field data who were supported by NSF Research Experience for Undergraduates (REU) program, and the Harvard Forest Woods Crew for logistical and maintenance support. 


\section{References}

Abramowitz, G., A. Pitman, H. Gupta, E. Kowalczyk, and Y. Wang (2007), Systematic Bias in Land Surface Models, Journal of Hydrometeorology, 8(5), 989-1001, doi:10.1175/JHM628.1.

Baldocchi, D. D. (1994), An analytical solution for coupled leaf photosynthesis and stomatal conductance models, Tree Physiology, 14, 1069-1079.

Ball, J. T., I. E. Woodrow, and J. A. Berry (1987), A model predicting stomatal conductance and its contribution to the control of photosynthesis under different environmental conditions, in Progress in Photosynthesis Research, edited by J. Biggins, pp. 221-224.

Barford, C. C., S. C. Wofsy, M. L. Goulden, J. W. Munger, E. H. Pyle, S. P. Urbanski, L. Hutyra, S. R. Saleska, D. Fitzjarrald, and K. Moore (2001), Factors controlling long- and short-term sequestration of atmospheric CO2 in a mid-latitude forest., Science, 294(5547), 1688-91, doi:10.1126/science.1062962.

Barrett, D. J., M. J. Hill, L. B. Hutley, J. Beringer, J. H. Xu, G. D. Cook, J. O. Carter, and R. J. Williams (2005), Prospects for improving savanna biophysical models by using multiple-constraints modeldata assimilation methods, Australian Journal of Botany, 53(7), 689-714, doi:10.1071/bt04139.

Beer, C. et al. (2010), Terrestrial gross carbon dioxide uptake: global distribution and covariation with climate., Science (New York, N.Y.), 329(5993), 834-8, doi:10.1126/science.1184984.

Bernacchi, C. J., E. L. Singsaas, C. Pimentel, a. R. Portis Jr, and S. P. Long (2001), Improved temperature response functions for models of Rubisco-limited photosynthesis, Plant, Cell and Environment, 24(2), 253-259, doi:10.1111/j.1365-3040.2001.00668.x.

Beven, K. (2006), A manifesto for the equifinality thesis, Journal of Hydrology, 320(1-2), 18-36. [online] Available from: http://www.sciencedirect.com/science/article/B6V6C-4H16S4M-

1/2/571c8821621c803522cc823147bef169 
Bishop, C. M. (1995), Neural Networks for Pattern Recognition, Oxford University Press, Oxford, U.K.

Bonan, G. B., P. J. Lawrence, K. W. Oleson, S. Levis, M. Jung, M. Reichstein, D. M. Lawrence, and S. C. Swenson (2011), Improving canopy processes in the Community Land Model version 4 (CLM4) using global flux fields empirically inferred from FLUXNET data, Journal of Geophysical Research, 116(G2), 1-22, doi:10.1029/2010JG001593.

Bousquet, P., P. Peylin, P. Ciais, C. Le Quéré, P. Friedlingstein, and P. P. Tans (2000), Regional changes in carbon dioxide fluxes of land and oceans since 1980., Science (New York, N.Y.), 290(5495), 13427.

Bowden, R. D., K. J. Nadelhoffer, R. D. Boone, J. Melillo, and J. B. Garrison (1993), Contributions of aboveground litter, belowground litter, and root respiration to total soil respiration in a temperate mixed hardwood forest, Canadian Journal of Forest Research, (23), 1402-1407.

Braswell, B. H., W. J. Sacks, E. Linder, and D. S. Schimel (2005), Estimating diurnal to annual ecosystem parameters by synthesis of a carbon flux model with eddy covariance net ecosystem exchange observations, Global Change Biology, 11(2), 335-355, doi:10.1111/j.1365-2486.2005.00897.x.

Campbell, G. S. (1986), Extinction coefficients for radiation in plant canopies calculated using an ellipsoidal inclination angle distribution, Agricultural and Forest Meteorology, 36, 371-321.

Clark, J. S. et al. (2001), Ecological forecasts: an emerging imperative., Science (New York, N.Y.), 293(5530), 657-60, doi:10.1126/science.293.5530.657.

Cox, P. M., R. a Betts, C. D. Jones, S. a Spall, and I. J. Totterdell (2000), Acceleration of global warming due to carbon-cycle feedbacks in a coupled climate model., Nature, 408(6809), 184-7, doi:10.1038/35041539.

Cramer, W. et al. (2001), Global response of terrestrial ecosystem structure and function to CO 2 and climate change: results from six dynamic global vegetation models, Global Change Biology, 7(4), 357-373, doi:10.1046/j.1365-2486.2001.00383.x. 
Delworth, T. L. et al. (2006), GFDL's CM2 Global Coupled Climate Models . Part I : Formulation and Simulation Characteristics, Journal of Climate, 19(5), 643-674.

Desai, A. R. (2010), Climatic and phenological controls on coherent regional interannual variability of carbon dioxide flux in a heterogeneous landscape, Journal of Geophysical Research, 115, 1-13, doi:10.1029/2010JG001423.

Dietze, M. et al. (2011), Characterizing the performance of ecosystem models across time scales: A spectral analysis of the North American Carbon Program site-level synthesis, Journal of Geophysical Research, (406), doi:10.1029/2011JG001661.

Dragoni, D., H. P. Schmid, C. A. Wayson, H. Potter, C. S. B. Grimmond, and J. C. Randolph (2011), Evidence of increased net ecosystem productivity associated with a longer vegetated season in a deciduous forest in south-central Indiana , USA, Global Change Biology, 17(2), 886-897, doi:10.1111/j.1365-2486.2010.02281.x.

Fahey, T. J. et al. (2005), The Biogeochemistry of Carbon at Hubbard Brook, Biogeochemistry, 75(1), 109-176, doi:10.1007/s10533-004-6321-y.

Fernandez, I. J., L. Rustad, and G. B. Lawrence (1993), Estimating total soil mass, nutrient content, andtrace metals in soils under a low elevation spruce-fir forest, Canadian Journal of Soil Science, (73), 317-328.

Fox, A. et al. (2009), The REFLEX project: Comparing different algorithms and implementations for the inversion of a terrestrial ecosystem model against eddy covariance data, Agricultural and Forest Meteorology, 149(10), 1597-1615, doi:10.1016/j.agrformet.2009.05.002.

Franks, S. W., K. J. Beven, and J. H. C. Gash (1999), Multi-objective conditioning of a simple SVAT model, Hydrol. Earth Syst. Sci., 3(4), 477-488, doi:10.5194/hess-3-477-1999.

Friedlingstein, P. et al. (2006), Climate-carbon cycle feedback analysis: Results from the (CMIP)-M-4 model intercomparison, Journal of Climate, 19(14), 3337-3353. 
Gaudinski, J. B., S. E. Trumbore, A. Eric, and S. Zheng (2000), Soil carbon cycling in a temperate forest : radiocarbon-based estimates of residence times, sequestration rates and partitioning of fluxes, Biogeochemistry, (51), 33-69.

Gedalof, Z., and A. a. Berg (2010), Tree ring evidence for limited direct CO 2 fertilization of forests over the 20th century, Global Biogeochemical Cycles, 24(3), 2-7, doi:10.1029/2009GB003699.

Gough, C. M., C. E. Flower, C. S. Vogel, D. Dragoni, and P. S. Curtis (2009), Whole-ecosystem labile carbon production in a north temperate deciduous forest, Agricultural and Forest Meteorology, 149, 1531-1540, doi:10.1016/j.agrformet.2009.04.006.

Goulden, M. L., J. W. Munger, S. M. Fan, B. C. Daube, and S. C. Wofsy (1996), Measurements of carbon sequestration by long-term eddy covariance: Methods and a critical evaluation of accuracy, Global Change Biology, 2(3), 169-182.

Hanson, P. J. et al. (2004), Oak Forest Carbon and Water Simulations: Model Intercomparisons and Evaluations Against Independent Data, Ecological Monographs, 74(3), 443-489, doi:10.1890/034049

Hastings, W. K. (1970), MONTE-CARLO SAMPLING METHODS USING MARKOV CHAINS AND THEIR APPLICATIONS, Biometrika, 57(1), 97

Hayhoe, K., C. Wake, B. Anderson, X.-Z. Liang, E. Maurer, J. Zhu, J. Bradbury, A. DeGaetano, A. M. Stoner, and D. Wuebbles (2007), Regional climate change projections for the Northeast USA, Mitigation and Adaptation Strategies for Global Change, 13(5-6), 425-436, doi:10.1007/s11027007-9133-2.

Heimann, M. et al. (1998), Evaluation of terrestrial carbon cycle models through simulations of the seasonal cycle of atmospheric First results of a model intercomparison study, Global Biogeochemical Cycles, 12(1), 1-24. 
Jolly, W. M., R. Nemani, and S. W. Running (2004), Enhancement of understory productivity by asynchronous phenology with overstory competitors in a temperate deciduous forest., Tree physiology, 24(9), 1069-71.

Keenan, T. F., M. S. Carbone, M. Reichstein, and A. D. Richardson (2011c), The model-data fusion pitfall: assuming certainty in an uncertain world, Oecologia, (167), 587-597, doi:10.1007/s00442011-2106-X.

Keenan, T. F., R. Grote, and S. Sabaté (2011b), Overlooking the canopy: The importance of canopy structure in scaling isoprenoid emissions from the leaf to the landscape, Ecological Modelling, 222(3), 737-747, doi:10.1016/j.ecolmodel.2010.11.004.

Keenan, T., J. Maria Serra, F. Lloret, M. Ninyerola, and S. Sabate (2011a), Predicting the future of forests in the Mediterranean under climate change, with niche- and process-based models: CO2 matters!, Global Change Biology, 17(1), 565-579, doi:10.1111/j.1365-2486.2010.02254.x.

Keenan, T.F. et al., (accepted article) Terrestrial biosphere model performance for inter-annual variability of land-atmosphere CO2 exchange. Global Change Biology. doi: 10.1111/j.13652486.2012.02678.x

Knorr, W., N. Gobron, M. Scholze, T. Kaminski, R. Schnur, and B. Pinty (2007), Impact of terrestrial biosphere carbon exchanges on the anomalous CO2 increase in 2002-2003, Geophysical Research Letters, 34(9), 1-6, doi:10.1029/2006GL029019.

Knorr, W., and J. Kattge (2005), Inversion of terrestrial ecosystem model parameter values against eddy covariance measurements by Monte Carlo sampling, Global Change Biology, 11(8), 1333-1351, doi:10.1111/j.1365-2486.2005.00977.x.

Lewis, S. L. et al. (2009), Increasing carbon storage in intact African tropical forests., Nature, 457(7232), 1003-6, doi:10.1038/nature07771. 
Long, S. P., E. a Ainsworth, A. D. B. Leakey, J. Nösberger, and D. R. Ort (2006), Food for thought: lower-than-expected crop yield stimulation with rising CO2 concentrations., Science (New York, N.Y.), 312(5782), 1918-21, doi:10.1126/science.1114722.

Luo, Y., J. Clark, T. Hobbs, S. Lakshmivarahan, A. Latimer, K. Ogle, D. Schimel, and X. Zhou (2008), Symposium 23. Toward Ecological Forecasting, Bulletin of the Ecological Society of America, 89(4), 467-474, doi:doi:10.1890/0012-9623

Luo, Y. et al. (2011), Coordinated approaches to quantify long-term ecosystem dynamics in response to global change, Global Change Biology, 17(2), 843-854, doi:10.1111/j.1365-2486.2010.02265.x.

le Maire, G. et al. (2010), Detecting the critical periods that underpin interannual fluctuations in the carbon balance of European forests, Journal of Geophysical Research, 115, 1-16, doi:10.1029/2009JG001244.

McMahon, S. M., G. G. Parker, and D. R. Miller (2010), Evidence for a recent increase in forest growth., Proceedings of the National Academy of Sciences of the United States of America, 107(8), 3611-5, doi:10.1073/pnas.0912376107.

Medvigy, D., S. C. Wofsy, J. W. Munger, D. Y. Hollinger, and P. R. Moorcroft (2009), Mechanistic scaling of ecosystem function and dynamics in space and time: Ecosystem Demography model version 2, Journal of Geophysical Research, 114(G1), 1-21, doi:10.1029/2008JG000812.

Metropolos, N., A. W. Rosenbluth, M. N. Rosenbluth, A. H. Teller, and E. Teller (1953), Equation of State Calculations by Fast Computing Machines, Journal of Chemical Physics, 21, 1087-1092.

Metropolos, N., and S. Ulam (1949), The Monte Carlo method, Journal of the American Statistical Association, 44, 351-341.

Moffat, A. M., C. Beckstein, G. Churkina, M. Mund, and M. Heimann (2010), Characterization of ecosystem responses to climatic controls using artificial neural networks, Global Change Biology, 16(10), 2737-2749, doi:10.1111/j.1365-2486.2010.02171.x. 
Moffat, A., D. Papale, M. Reichstein, D. Hollinger, A. Richardson, A. Barr, C. Beckstein, B. Braswell, G. Churkina, and A. Desai (2007), Comprehensive comparison of gap-filling techniques for eddy covariance net carbon fluxes, Agricultural and Forest Meteorology, 147(3-4), 209-232, doi:10.1016/j.agrformet.2007.08.011.

Munger, J. W. W. et al. (1998), Regional budgets for nitrogen oxides from continental sources: variations of rates for oxidation and deposition with season and distance from source regions, Journal of Geophysical Research, 103, 8355-8368.

van Oijen, M., D. R. Cameron, K. Butterbach-Bahl, N. Farahbakhshazad, P.-E. Jansson, R. Kiese, K.-H. Rahn, C. Werner, and J. B. Yeluripati (2011), A Bayesian framework for model calibration, comparison and analysis: Application to four models for the biogeochemistry of a Norway spruce forest, Agricultural and Forest Meteorology, 151(12), 1609-1621, doi:10.1016/j.agrformet.2011.06.017.

Pan, Y. et al. (2011), A Large and Persistent Carbon Sink in the World's Forests, Science, 14(July), 1-11, doi:10.1126/science.1201609.

Phillips, S. C., R. K. Varner, S. Frolking, J. W. Munger, J. L. Bubier, S. C. Wofsy, and P. M. Crill (2010), Interannual, seasonal, and diel variation in soil respiration relative to ecosystem respiration at a wetland to upland slope at Harvard Forest, Journal of Geophysical Research-Biogeosciences, 115(G2), 1-18, doi:G02019 10.1029/2008jg000858.

Pilegaard, K., A. Ibrom, M. S. Courtney, P. Hummelshøj, and N. O. Jensen (2011), Increasing net CO2 uptake by a Danish beech forest during the period from 1996 to 2009, Agricultural and Forest Meteorology, 151(7), 934-946, doi:10.1016/j.agrformet.2011.02.013.

Planet, E., D.-sea Res, O. D. P. Sci, W. Knorr, I. C. Prentice, J. I. House, and E. A. Holland (2005), Longterm sensitivity of soil carbon turnover to warming, Nature, 433(January), 298-301, doi:10.129/2002PA000837. 
Press, W. H., S. A. Teukolsky, W. T. Vetterling, and B. P. Flannery (2007), Numerical Receipes: The art of scientific computing, Cambridge University Press, Cambridge UK.

De Pury, D. G. G., and G. D. Farquhar (1997), Simple scaling of photosynthesis from leaves to canopies without the errors of big-leaf models, Plant, Cell and Environment, 20(5), 537-557, doi:10.1111/j.1365-3040.1997.00094.x.

Raupach, M. R., P. J. Rayner, D. J. Barrett, R. S. DeFries, M. Heimann, D. S. Ojima, S. Quegan, and C. C. Schmullius (2005), Model-data synthesis in terrestrial carbon observation: methods, data requirements and data uncertainty specifications, Global Change Biology, 11(3), 378-397, doi:10.1111/j.1365-2486.2005.00917.x.

Ricciuto, D.M., A.W. King, D. Dragoni, and W. M. Post (2011),Parameter and prediction uncertainty in an optimized terrestrial carbon cycle model: Effects of constraining variables and data record length. Journal of Geophysical Research-Biogeosciences, 116. , G01033, doi:10.1029/2010JG001400

Richardson, A. D., D. Y. Hollinger, J. D. Aber, S. V. Ollinger, and B. H. Braswell (2007), Environmental variation is directly responsible for short- but not long-term variation in forest-atmosphere carbon exchange, Global Change Biology, 13(4), 788-803, doi:10.1111/j.1365-2486.2007.01330.x.

Richardson, A. D. et al. (2006), A multi-site analysis of random error in tower-based measurements of carbon and energy fluxes, Agricultural and Forest Meteorology, 136(1-2), 1-18, doi:10.1016/j.agrformet.2006.01.007.

Richardson, A. D. et al. (2010), Estimating parameters of a forest ecosystem C model with measurements of stocks and fluxes as joint constraints., Oecologia, 164(1), 25-40, doi:10.1007/s00442-010-1628$\mathrm{y}$.

Rojas, R. (1996), Neural Networks - A Systematic Introduction, Springer Berlin / Heidelberg, Heidelberg.

Salzer, M. W., M. K. Hughes, A. G. Bunn, and K. F. Kipfmueller (2009), Recent unprecedented tree-ring growth in bristlecone pine at the highest elevations and possible causes., Proceedings of the 
National Academy of Sciences of the United States of America, 106(48), 20348-53, doi:10.1073/pnas.0903029106.

Savage, K., E. a. Davidson, A. D. Richardson, and D. Y. Hollinger (2009), Three scales of temporal resolution from automated soil respiration measurements, Agricultural and Forest Meteorology, 149(11), 2012-2021, doi:10.1016/j.agrformet.2009.07.008.

Schwalm, C. R. et al. (2010), A model-data intercomparison of CO 2 exchange across North America: Results from the North American Carbon Program site synthesis, Journal of Geophysical Research, 115, 22, doi:10.1029/2009JG001229.

Sinclair, T. R., C. E. Murphy, and K. R. Knoerr (1976), Development and evaluation of simplified models for simulating canopy photosynthesis and transpiration, Journal of Applied Ecology, 13, 813-829.

Siqueira, M. B., G. G. Katul, D. a. Sampson, P. C. Stoy, J.-Y. Juang, H. R. Mccarthy, and R. Oren (2006), Multiscale model intercomparisons of $\mathrm{CO} 2$ and $\mathrm{H} 2 \mathrm{O}$ exchange rates in a maturing southeastern US pine forest, Global Change Biology, 12(7), 1189-1207, doi:10.1111/j.1365-2486.2006.01158.x.

Sitch, S. et al. (2008), Evaluation of the terrestrial carbon cycle, future plant geography and climatecarbon cycle feedbacks using five Dynamic Global Vegetation Models (DGVMs), Global Change Biology, 14(9), 2015-2039, doi:10.1111/j.1365-2486.2008.01626.x.

Solomon, S., D. Qin, M. Manning, Z. Chen, and M. Marq (Eds.) (2007), IPCC 2007 Summary for policymakers. In Climate change 2007: the physical science basis. Contribution of working group I to the fourth assessment report of the intergovernmental panel on climate change.

Urbanski, S., C. Barford, S. Wofsy, C. Kucharik, E. Pyle, J. Budney, K. McKain, D. Fitzjarrald, M. Czikowsky, and J. W. Munger (2007), Factors controlling CO 2 exchange on timescales from hourly to decadal at Harvard Forest, Journal of Geophysical Research, 112(G2), 1-25, doi:10.1029/2006JG000293. 
WANG, Y. P., D. BALDOCCHI, R. LEUNING, E. FALGE, and T. VESALA (2007), Estimating parameters in a land-surface model by applying nonlinear inversion to eddy covariance flux measurements from eight FLUXNET sites, Global Change Biology, 13(3), 652-670, doi:10.1111/j.1365-2486.2006.01225.x

Wang, Y., and R. Leuning (1998), A two-leaf model for canopy conductance, photosynthesis and partitioning of available energy I : Model description and comparison with a multi-layered model, Agricultural and Forest Meteorology, 91.

Wang, Y.-P. P., C. M. Trudinger, and I. G. Enting (2009), A review of applications of model-data fusion to studies of terrestrial carbon fluxes at different scales, Agricultural and Forest Meteorology, 149(11), 1829-1842, doi:10.1016/j.agrformet.2009.07.009.

Weng, E., and Y. Luo (2011), Relative information contributions of model vs. data to short- and long-term forecasts of forest carbon dynamics., Ecological applications : a publication of the Ecological Society of America, 21(5), 1490-505.

Williams, M. et al. (2009), Improving land surface models with FLUXNET data, Biogeosciences, 6(7), 1341-1359, doi:10.5194/bg-6-1341-2009.

Williams, M., P. A. Schwarz, B. E. Law, J. Irvine, and M. R. Kurpius (2005), An improved analysis of forest carbon dynamics using data assimilation, Global Change Biology, 11(1), 89-105, doi:10.1111/j.1365-2486.2004.00891.x.

Wofsy, S. C., M. L. Goulden, J. W. Munger, S. M. Fan, P. S. Bakwin, B. C. Daube, S. L. Bassow, and F. a Bazzaz (1993), Net Exchange of CO2 in a Mid-Latitude Forest, Science (New York, N.Y.), 260(5112), 1314-7, doi:10.1126/science.260.5112.1314.

Xu, T., L. White, D. Hui, and Y. Luo (2006), Probabilistic inversion of a terrestrial ecosystem model: Analysis of uncertainty in parameter estimation and model prediction, Global Biogeochemical Cycles, 20(2), 1-15, doi:10.1029/2005GB002468. 
Zaehle, S., and a. D. Friend (2010), Carbon and nitrogen cycle dynamics in the O-CN land surface model:

1. Model description, site-scale evaluation, and sensitivity to parameter estimates, Global

Biogeochemical Cycles, 24(1), 1-13, doi:10.1029/2009GB003521

Zeng, N., A. Mariotti, and P. Wetzel (2005), Terrestrial mechanisms of interannual CO 2 variability, Global Biogeochemical Cycles, 19(1), GB1061, doi:10.1029/2004GB002273.

Table 1. Data sets used in this study

$\begin{array}{llll}\text { Measurement } & \text { Frequency } & \text { \# data } & \text { Reference } \\ & & \text { points } & \\ \text { Eddy-covariance } & \text { Hourly } & 73,198 & \text { Urbanski et al., and }{ }^{1} \\ \text { Soil Respiration 1 } & \text { Hourly } & 26,430 & \text { Savage et al., 2009 }\end{array}$

\begin{tabular}{|c|c|c|c|}
\hline Soil Respiration 2 & Hourly & 19,030 & Phillips et al., 2010 \\
\hline Soil Respiration 3 & Weekly & 498 & 2 \\
\hline \multirow[t]{2}{*}{ Leaf area index } & Monthly & 51 & Norman, 1993; \\
\hline & & & Urbanski et al., and ${ }^{1}$ \\
\hline Leaf litter fall & Yearly & 10 & Urbanski et al., and ${ }^{1}$ \\
\hline \multirow[t]{2}{*}{ Woody biomass } & Yearly & 15 & Jenkins et al., 2004. \\
\hline & & & Urbanski et al., and ${ }^{1}$ \\
\hline Woody litterfall & Yearly & 8 & Urbanski et al., and ${ }^{1}$ \\
\hline Root biomass & One Year & 1 & DIRT project ${ }^{1}$ \\
\hline
\end{tabular}

Forest floor carbon One Year $1 \quad$ Gaudinski et al., 2000

$\begin{array}{llll}\text { Budburst } & \text { Yearly } & 15 & \text { O'Keefe, }^{\prime} 2000^{1}\end{array}$




$\begin{array}{llll}\begin{array}{l}\text { Leaf Drop } \\ \text { Soil carbon pools }\end{array} & \text { Yearly } & 14 & \text { O'Keefe, 2000 }^{1} \\ & \text { Three years } & 3 & \text { Gaudinski et al., } 2000 \\ & & & \text { Magill et al., 2000 } \\ \begin{array}{l}\text { Soil carbon turnover } \\ \begin{array}{l}\text { Proportion of } \\ \text { One }\end{array}\end{array} & 1 & \text { Bowden et al., 2009 } \\ \text { heterotrophic } & \text { One } & 1 & \text { Gaudinski et al., } 2000 \\ \text { respiration in soil } & & & \end{array}$

${ }^{1}$ See data download page: http://harvardforest.fas.harvard.edu/data/archive.html

${ }^{2} \mathrm{ftp} / / / \mathrm{ftp}$. as.harvard.edu/pub/nigec/HU_Wofsy/hf_data/ecological_data/soilR/ 
Table 2. FöBAAR model parameters and pools. Both parameters and initial pool sizes were optimized conditional on the data constraints. The posterior $90 \%$ confidence interval for each parameter is given, based on optimization to Period 2 using all data constraints.

\begin{tabular}{|c|c|c|c|c|c|}
\hline Id. & Name & Definition & Min & Max & $90 \% \mathrm{CI}$ \\
\hline & & \multicolumn{4}{|c|}{ Initial Carbon Pools $\left(\mathrm{g} \mathrm{C} \mathrm{m}^{-2}\right)$} \\
\hline $\mathbf{P 1}$ & $\mathrm{R}_{\mathrm{C}}$ & Carbon in roots & 20 & 500 & $(28,205)$ \\
\hline $\mathbf{P 2}$ & $\mathrm{W}_{\mathrm{C}}$ & Carbon in wood & 8000 & 14000 & $(7792,10931)$ \\
\hline P3 & $\mathrm{Lit}_{\mathrm{C}}$ & Carbon in litter & 10 & 1000 & $(146,528)$ \\
\hline $\mathbf{P 4}$ & $\mathrm{SOM}_{\mathrm{C}}$ Slow & $\begin{array}{l}\text { Carbon in slow cycling soil organic } n \\
\text { layer }\end{array}$ & 10 & 1000 & $(95,278)$ \\
\hline P5 & $\mathrm{SOM}_{\mathrm{C}}$ Passive & $\begin{array}{l}\text { Carbon in passive cycling soil organic } n \\
\text { layer }\end{array}$ & 1500 & 12000 & $(1800,4560)$ \\
\hline P6 & $\operatorname{Mob}_{\mathrm{C}}$ & Mobile carbon & 75 & 200 & $(90,175)$ \\
\hline \multicolumn{6}{|c|}{ Allocation and Transfer Parameters } \\
\hline P7 & Af & Fraction of GPP allocated to foliage & 0.1 & 1 & $(0.31,0.48)$ \\
\hline P8 & $\mathrm{Ar}$ & Fraction of NPP allocated to roots & 0.5 & 1 & $(0.57,0.83)$ \\
\hline P9 & $\mathrm{Lf}_{\mathrm{f}}$ & Litterfall from foliage $\left(\log _{10}\right)$ & -6 & -0.85 & $(-1.12,-0.88)$ \\
\hline P10 & $\mathrm{Lf}_{\mathrm{w}}$ & Litterfall from wood $\left(\log _{10}\right)$ & -6 & -1 & $(-5.14,-4.88)$ \\
\hline P11 & $\mathrm{Lf}_{\mathrm{r}}$ & Litterfall from roots $\left(\log _{10}\right)$ & -6 & -1 & $(-2.62,-1.88)$ \\
\hline P12 & Fc_lf & Fraction of $\mathrm{Cf}$ not transferred to mobile c & 0.3 & 0.8 & $(0.36,0.52)$ \\
\hline
\end{tabular}



$\mathbf{P 1 3} \mathrm{Lit}_{2} \mathrm{SOM} \quad$ Litter to slow $\mathrm{SOM}_{\mathrm{C}}$ transfer rate $\left(\log _{10}\right) \quad-6 \quad-1 \quad-1 \quad(-2.79,-2.09)$
P14 Lit $_{2} \mathrm{SOM} \mathrm{T}_{\mathrm{d}} \quad$ Litter to slow SOM $\mathrm{C}_{\mathrm{C}}$ temperature depende $0.01 \quad 0.5 \quad(0.01,0.07)$
$\mathbf{P 1 5} \mathrm{SOM}_{\mathrm{S} 2} \mathrm{SOM}_{\mathrm{P}} \quad$ Slow $\mathrm{SOM}_{\mathrm{C}}$ to passive $\mathrm{SOM}_{\mathrm{C}}$ rate $\quad 0.03 \quad 0.8 \quad(0.07,0.77)$
P16 $\mathrm{SOM}_{\mathrm{S} 2} \mathrm{SOM}_{\mathrm{P}}$ ] Slow $\mathrm{SOM}_{\mathrm{C}}$ to passive $\mathrm{SOM}_{\mathrm{C}} \begin{array}{rrrr}1 & & & \\ & 0.01 & 0.8 & (0.03,0.55)\end{array}$ dependence

\section{Canopy Parameters}

\begin{tabular}{|c|c|c|c|c|c|}
\hline $\mathbf{P 1 7}$ & LMA & Leaf mass per area $\left(\mathrm{g} \mathrm{C} \mathrm{m}^{-2}\right)$ & 50 & 120 & $(81,120)$ \\
\hline P18 & MaxFol & Maximum canopy carbon content $\left(\mathrm{g} \mathrm{C} \mathrm{m}^{-}\right.$ & 150 & 600 & $(180,550)$ \\
\hline P19 & $\mathrm{Vc}_{\max }$ & Velocity of carboxylation ( $\mathrm{umol} \mathrm{mol}^{-1}$ ) & 60 & 175 & $(90,165)$ \\
\hline $\mathbf{P 2 0}$ & Ea Vcmax & Activation energy for Vcmax & 58000 & 75000 & $(58000,75000)$ \\
\hline $\mathbf{P 2 1}$ & Ed Vcmax & Deactivation energy for $V c m a x$ & 20000 & 250000 & $(200000,250000)$ \\
\hline $\mathbf{P 2 2}$ & Ea Jmax & $\begin{array}{l}\text { Activation energy for the electron tran } \\
\text { rate }\end{array}$ & 40000 & 50000 & $(40000,50000)$ \\
\hline
\end{tabular}

P23 Ed Jmax Deactivation energy for the electron tran $1800023000($ (180000,230000) rate
P24 Rd
Rate of dark respiration
$0.01 \quad 1.1 \quad(0.01,1.1)$
P25 Q10 Rd
Temperature dependence of $\mathrm{Rd}$
$0.4 \quad 2.8 \quad(0.45,2.75)$

\section{Phenology Parameters}

\begin{tabular}{|c|c|c|c|c|c|}
\hline P26 & $\mathrm{GDD}_{0}$ & Day of year for growing degree day initial & 50 & 150 & $(91,117)$ \\
\hline P27 & $\mathrm{GDD}_{1}$ & Growing degree days for spring onset & 135 & 300 & $(135,277)$ \\
\hline P28 & $\operatorname{AirT}_{\mathrm{s}}$ & $\begin{array}{l}\text { Leaf senescence onset mean air temper } \\
\left({ }^{\circ} \mathrm{C}\right)\end{array}$ & 0 & 15 & $(11,12.4)$ \\
\hline P29 & $\mathrm{GDD}_{2}$ & Spring photosynthetic GDD maximum & 500 & 1000 & $(660,1000)$ \\
\hline
\end{tabular}




\begin{tabular}{|c|c|c|c|c|c|}
\hline P30 & $\mathrm{Lit}_{\mathrm{d}}$ & Litter respiration rate $\left(\log _{10}\right)$ & -7 & -1 & $(-6.6,-3.7)$ \\
\hline P31 & $\operatorname{Lit}_{d} T_{d}$ & Litter respiration temperature dependence & 0.001 & 0.1 & $(0.01,0.1)$ \\
\hline P32 & $\mathrm{SOM}_{\mathrm{Sd}}$ & Slow cycling $\mathrm{SOM}_{\mathrm{C}}$ respiration rate $\left(\log _{1}\right.$ & -6 & -1 & $(-4.55,3.11)$ \\
\hline P33 & $\mathrm{SOM}_{\mathrm{Sd}} \mathrm{T}_{\mathrm{d}}$ & Slow cycling $\mathrm{SOM}_{\mathrm{C}}$ temperature depende & 0.01 & 0.2 & $(0.01,0.19)$ \\
\hline P34 & $\mathrm{SOM}_{\mathrm{Pd}}$ & Passive cycling $\mathrm{SOM}_{\mathrm{C}}$ respiration rate $(\mathrm{Lc}$ & -6 & -1 & $(-6.38,-5.15)$ \\
\hline P35 & $\operatorname{Rroot}_{\mathrm{d}}$ & Root respiration rate $\left(\log _{10}\right)$ & -6 & -1 & $(-5.09,-3.77)$ \\
\hline P36 & $\operatorname{Rroot}_{d} T_{d}$ & Root respiration rate temperature depende & 0.01 & 0.2 & $(0.07,0.2)$ \\
\hline P37 & $\operatorname{Mob}_{\mathrm{Cr}}$ & Mobile stored carbon respiration rate (Lọ & -6 & -0.5 & $(-1.5,0.5)$ \\
\hline P38 & $\operatorname{Mob}_{C} T_{r}$ & Fraction of mobile transfers respired & 0 & 0.1 & $(0,0.1)$ \\
\hline P39 & Maint $_{r}$ & Fraction of GPP respired for maintenance & 0.1 & 0.5 & $(0.1,0.44)$ \\
\hline
\end{tabular}

P40 Rsoil 1 Soil respiration scaling co-efficient (data $\quad 0.522 \quad(0.96,1.65)$

P41 Rsoil $_{2} \quad$ Soil respiration scaling co-efficient (data $: 0.5 \quad 2 \quad(0.62,1.53)$

$\mathbf{P 4 2} \mathrm{Rsoil}_{3} \quad$ Soil respiration scaling co-efficient (data $: 0.5 \quad 2 \quad(0.45,1.65)$ 
Table 3. Performance metrics for all data streams used in the FöBAAR model, and net ecosystem exchange for the ANN. See Table 1 for a description of the data used. All non-zero $\mathrm{r}^{2}$ values are significant for $\mathrm{p}<0.05$; n.s. $=>$ no significant relation found.

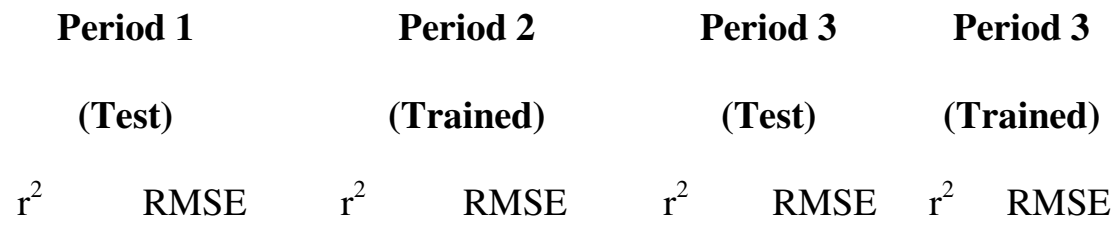

$\begin{array}{lclllll}\text { ANNe } & & & & & & \\ \text { NEE Day } & 0.77 & 0.17 & 0.74 & 0.19 & 0.76 & 0.22 \\ \text { NEE Night } & 0.11 & 0.10 & 0.17 & 0.10 & 0.19 & 0.10 \\ \text { NEE Annual } & \text { n.s. } & 118.18 & \text { n.s. } & 73.40 & \text { n.s. } & 213.80\end{array}$

FöBAAR

$\begin{array}{lcccccccc}\text { NEE Day } & 0.79 & 0.16 & 0.76 & 0.19 & 0.75 & 0.25 & 0.78 & 0.20 \\ \text { NEE Night } & 0.09 & 0.11 & 0.15 & 0.11 & 0.10 & 0.11 & 0.14 & 0.11 \\ \text { NEE Annual } & \text { n.s. } & 63.23 & \text { n.s. } & 90.57 & \text { n.s. } & 298.27 & \text { n.s. } & 87.3 \\ \text { Soil Respiration } & \text { n.s. } & \text { n.s. } & 0.90 & 0.68 & 0.71 & 1.17 & 0.70 & 1.08 \\ \text { Leaf Area Index } & 0.89 & 0.86 & 0.89 & 0.49 & 0.76 & 0.85 & 0.84 & 0.71 \\ \text { Litter fall } & \text { n.s. } & \text { n.s. } & \text { n.s. } & 11.58 & \text { n.s. } & 50.56 & \text { n.s. } & 13.34 \\ \text { Woody biomass } & \text { 1.00 } & 60.15 & 0.96 & 52.93 & 0.99 & 111.44 & 0.99 & 56.08 \\ \text { Woody } & & & & & & & & \\ \text { increment } & \text { n.s. } & 0.01 & \text { n.s. } & 0.06 & \text { n.s. } & 0.15 & \text { n.s. } & 0.02\end{array}$




$\begin{array}{lllllllll}\text { Bud Burst } & 0.20 & 4.24 & 0.24 & 4.17 & 0.21 & 3.70 & 0.32 & 0.57 \\ \text { Leaf Drop } & 0.17 & 5.74 & 0.35 & 3.42 & 0.18 & 3.68 & 0.18 & 3.68\end{array}$

FöBAAR vs

ANNe

$\begin{array}{lcccccc}\text { NEE Day } & 0.76 & 0.18 & 0.76 & 0.18 & 0.71 & 0.21 \\ \text { NEE Night } & 0.62 & 0.06 & 0.63 & 0.05 & 0.54 & 0.06 \\ \text { NEE Annual } & \text { n.s. } & 79.18 & \text { n.s. } & 70.58 & \text { n.s. } & 80.70\end{array}$




\section{Figures:}

Figure 1 Model uncertainty for NEE, GPP, Ra and Rh, for the FöBAAR model. The FöBAAR model was constrained on data in Period 2, and tested on periods 1 and 3. Three different approaches to constraining the model are shown: 1) Using all data available (flux and biometric, black), 2) Using hourly tower measurements of NEE, and monthly and annual aggregates (dark grey), 3) using only hourly tower measurements of NEE (light grey). The shaded areas thus represent the confidence in model projections, without a direct comparison to data.

Figure 2 Measured (line) and modeled (light grey area) annual NEE with the FöBAAR model trained on data from Period 2. Horizontal dark grey bars represent measured means for each period.

Figure 3 The daily NEE residuals (modelled-measured, $\mathrm{gC} \mathrm{m}^{-2} \mathrm{~d}^{-1}$ ) for FöBAAR and the ANN, showing the seasonal cycle of data-model mismatch, when both models are trained on Period 2. The residuals are shown in polar plots, where a full circle corresponds to 1 year, and monthly intervals are represented by the initial letter of the month. The zero residual is indicated by the inner black circle (solid line). The smoothed line (red, solid) is a 7-day moving average mean based on all years of data in each period. 
Figure 4 The cumulative daily NEE residuals (modeled-measured, $\mathrm{gC} \mathrm{m}^{-2}$ ) for FöBAAR when trained on each period individually and tested on the other two periods. The red line represents the mean cumulative residual for each 6-year period, and the grey area is one standard deviation about the mean. The dashed black line represents the zero residual.

Figure 5 The co-varying posterior distribution of $V c_{\max }$ and the proportion of gross primary productivity (GPP) respired for maintenance, for the FöBAAR model calibrated independently on each of the three 6-year periods (Fig. 2). Contour lines represent the mean annual GPP $\left(\mathrm{gC} \mathrm{m}^{-2} \mathrm{yr}^{-1}\right)$ for a particular combination of parameters.

Figure 6 FöBAAR model projections to 2100 for carbon fluxes (top, $\mathrm{gC} \mathrm{m}^{-2} \mathrm{y}^{-1}$ ) and pools (bottom, $\mathrm{kgC} \mathrm{m}^{-2}$ ) from 2000 to 2100 , using posterior parameters from a model optimization using: 1) Only hourly net ecosystem exchange fluxes (dark grey); 2) hourly, monthly and annual net ecosystem exchange fluxes (medium grey); 3) all flux and ancillary data (light grey) (Table 3). Shaded areas represent $90 \%$ confidence limits on model projections, generated by parameter sets taken from the posterior parameter distribution. 


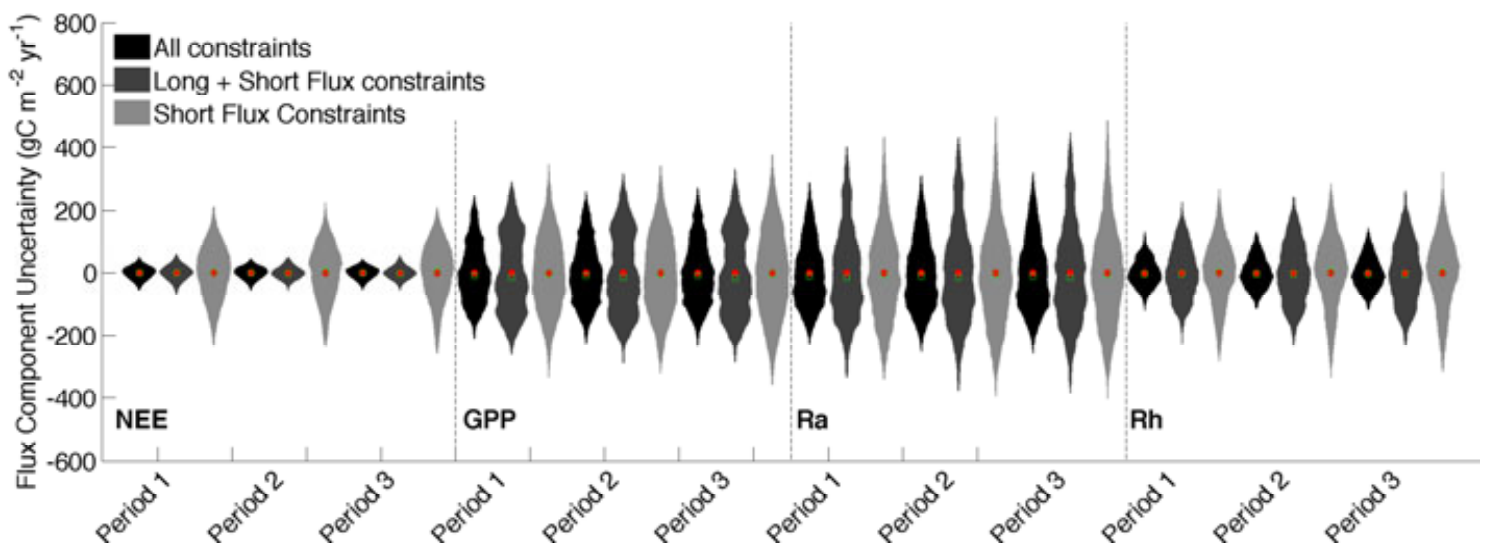




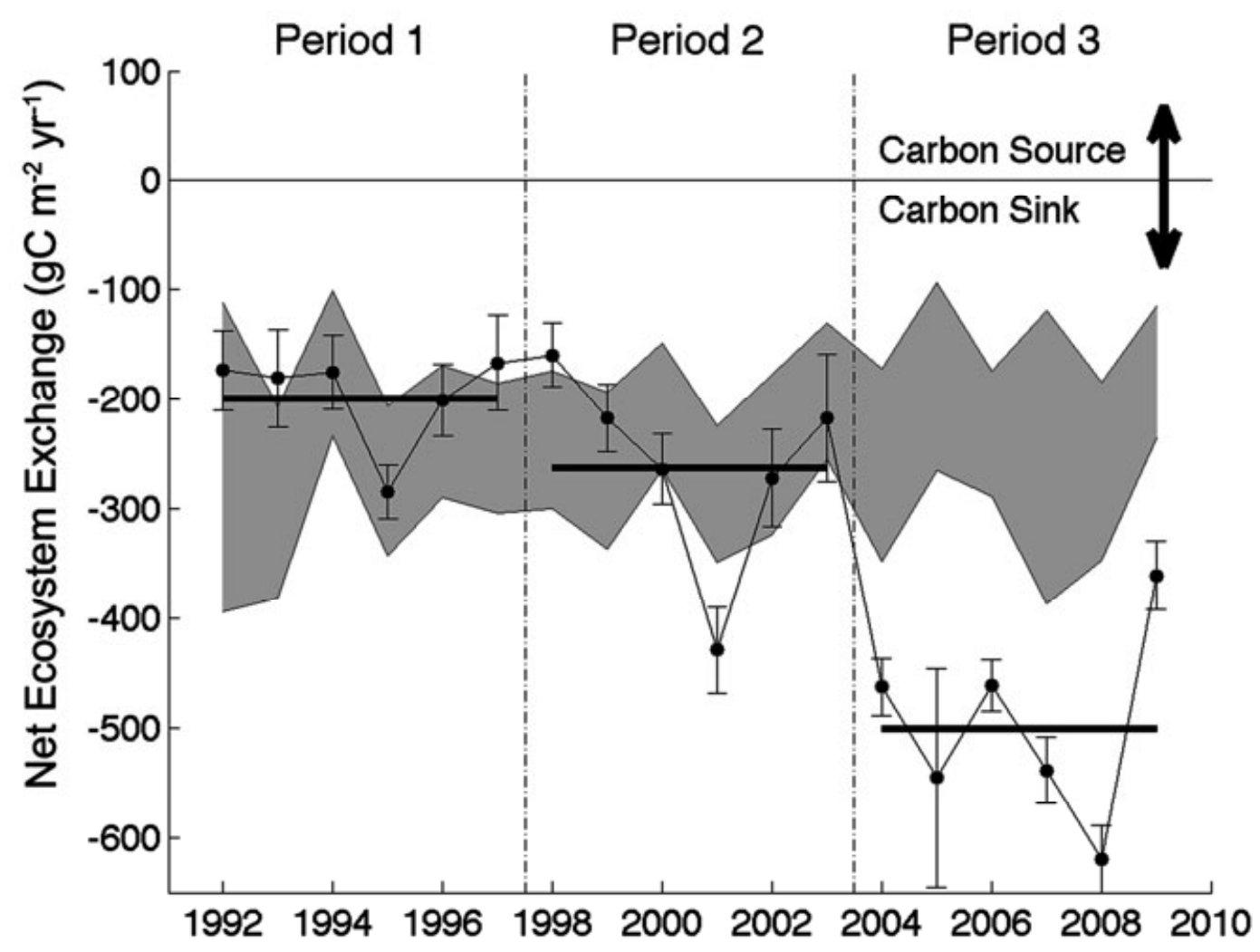



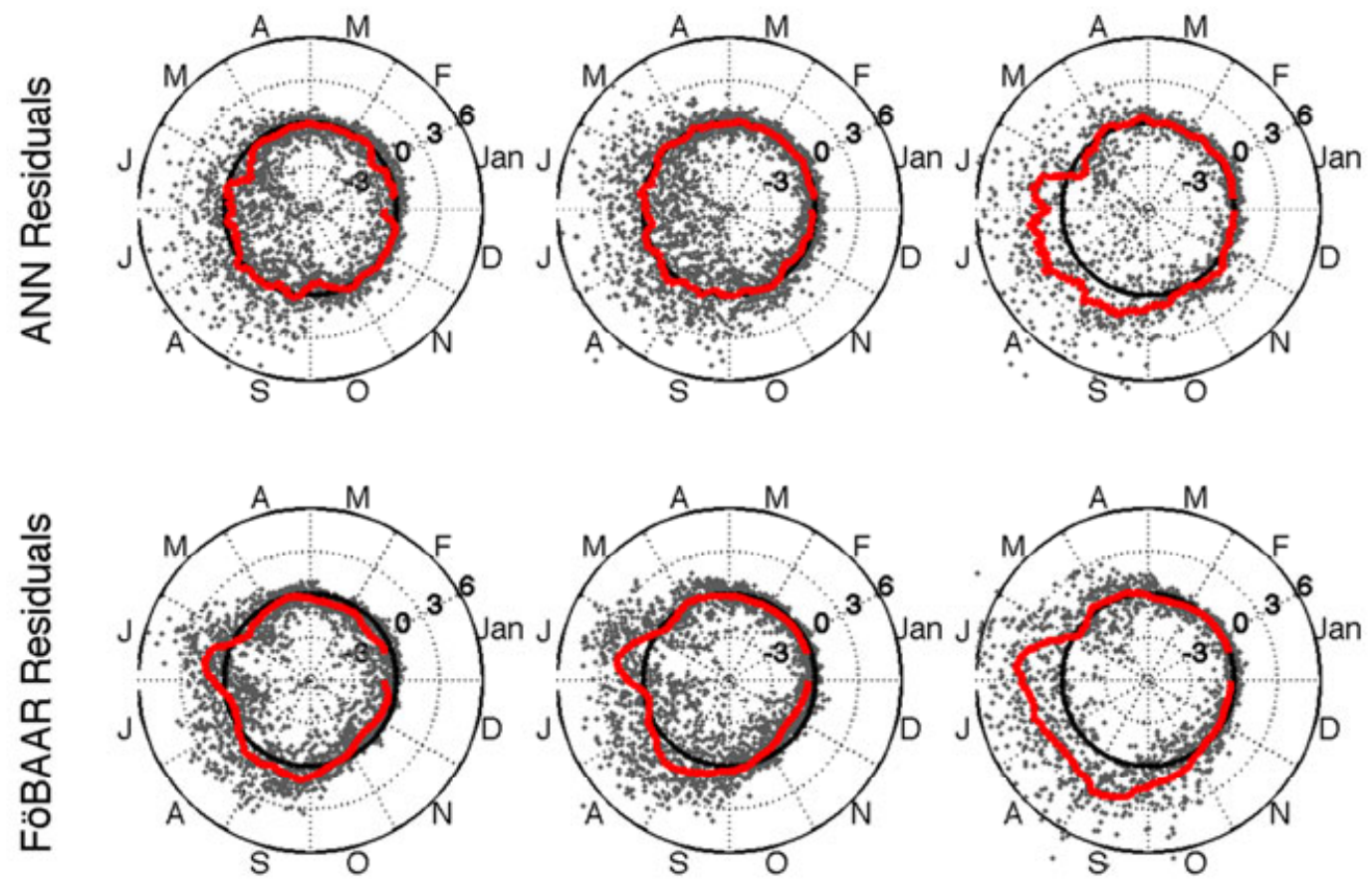

Period 1 (Test) Period 2 (Training) Period 3 (Test) 


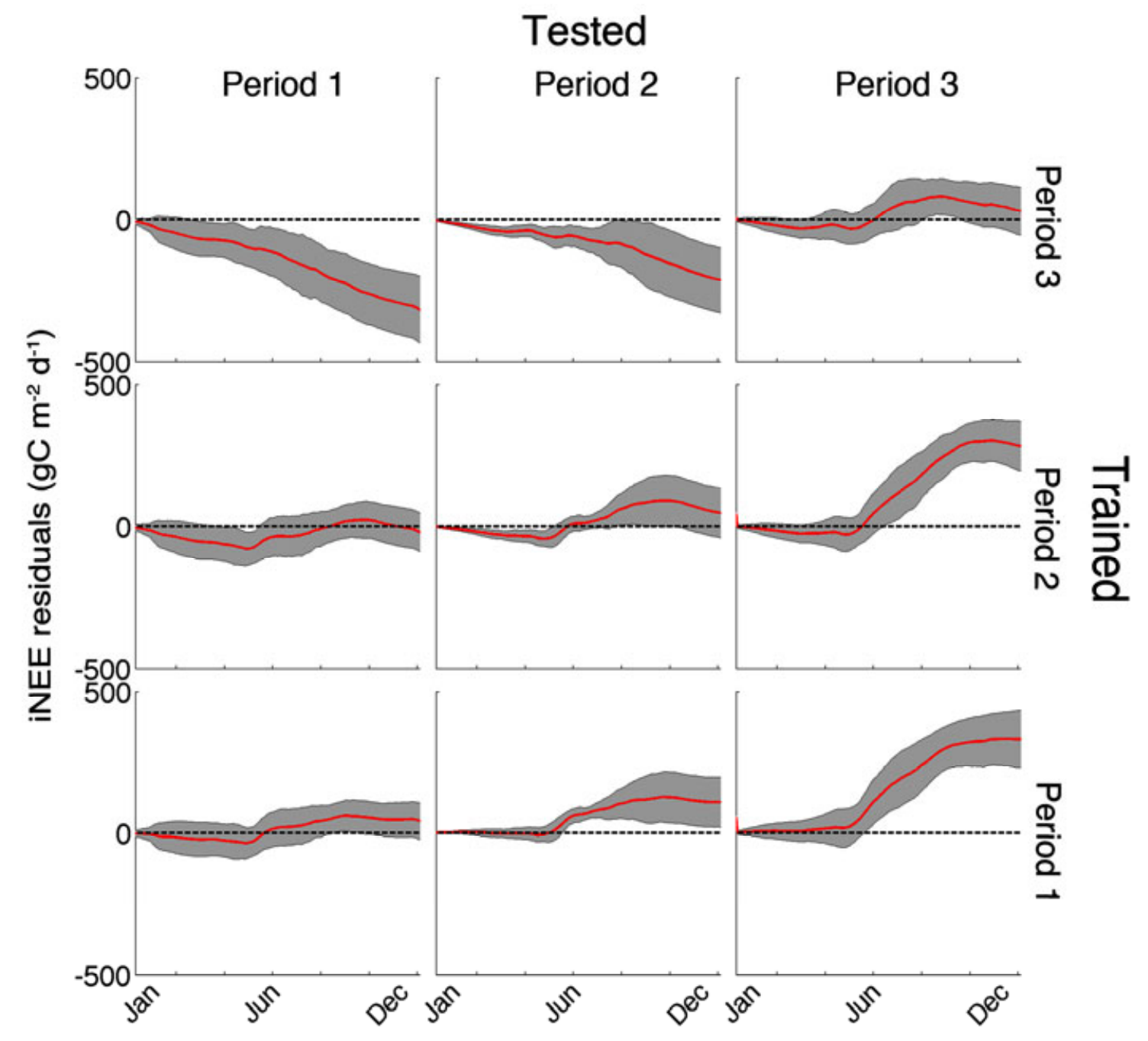




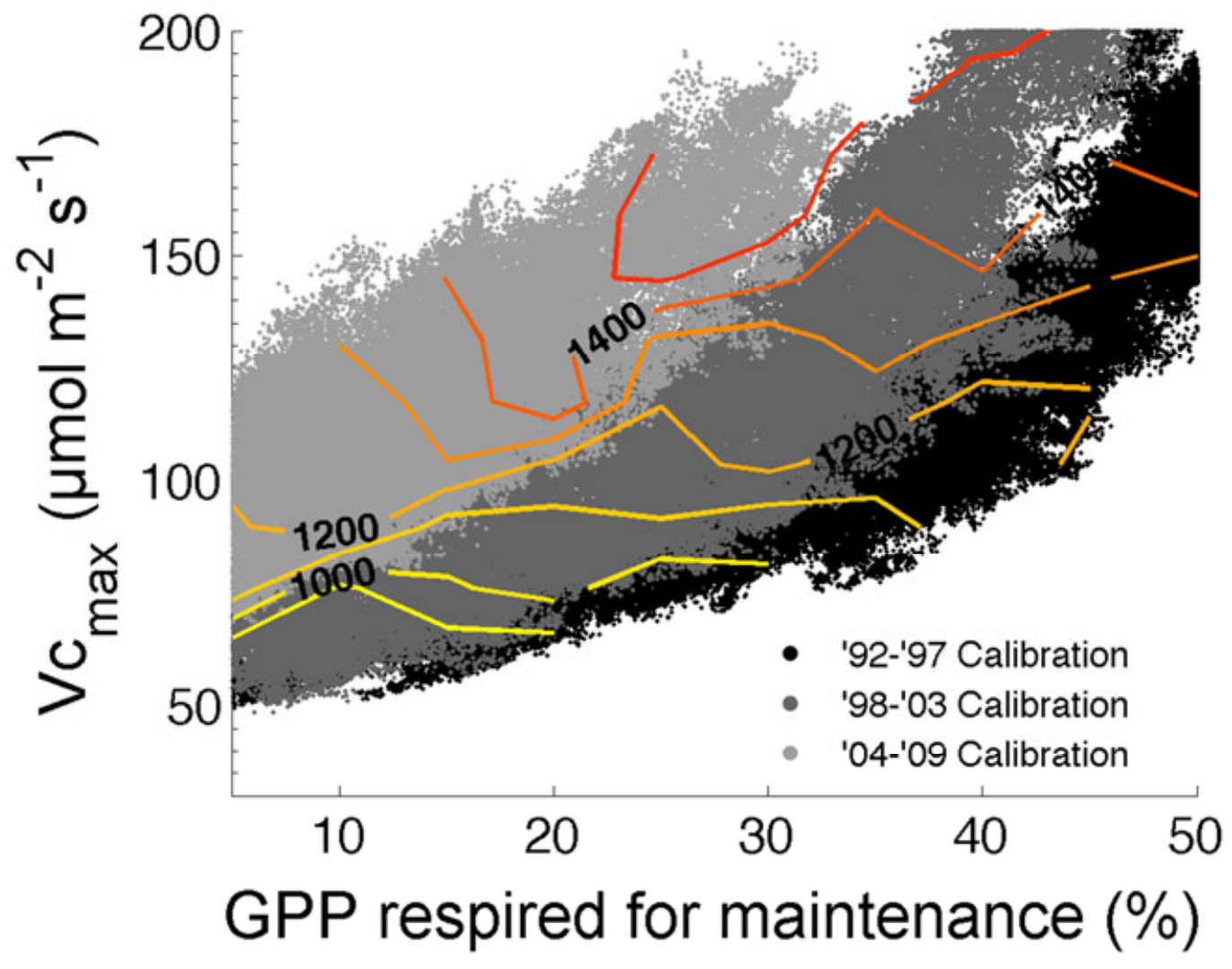




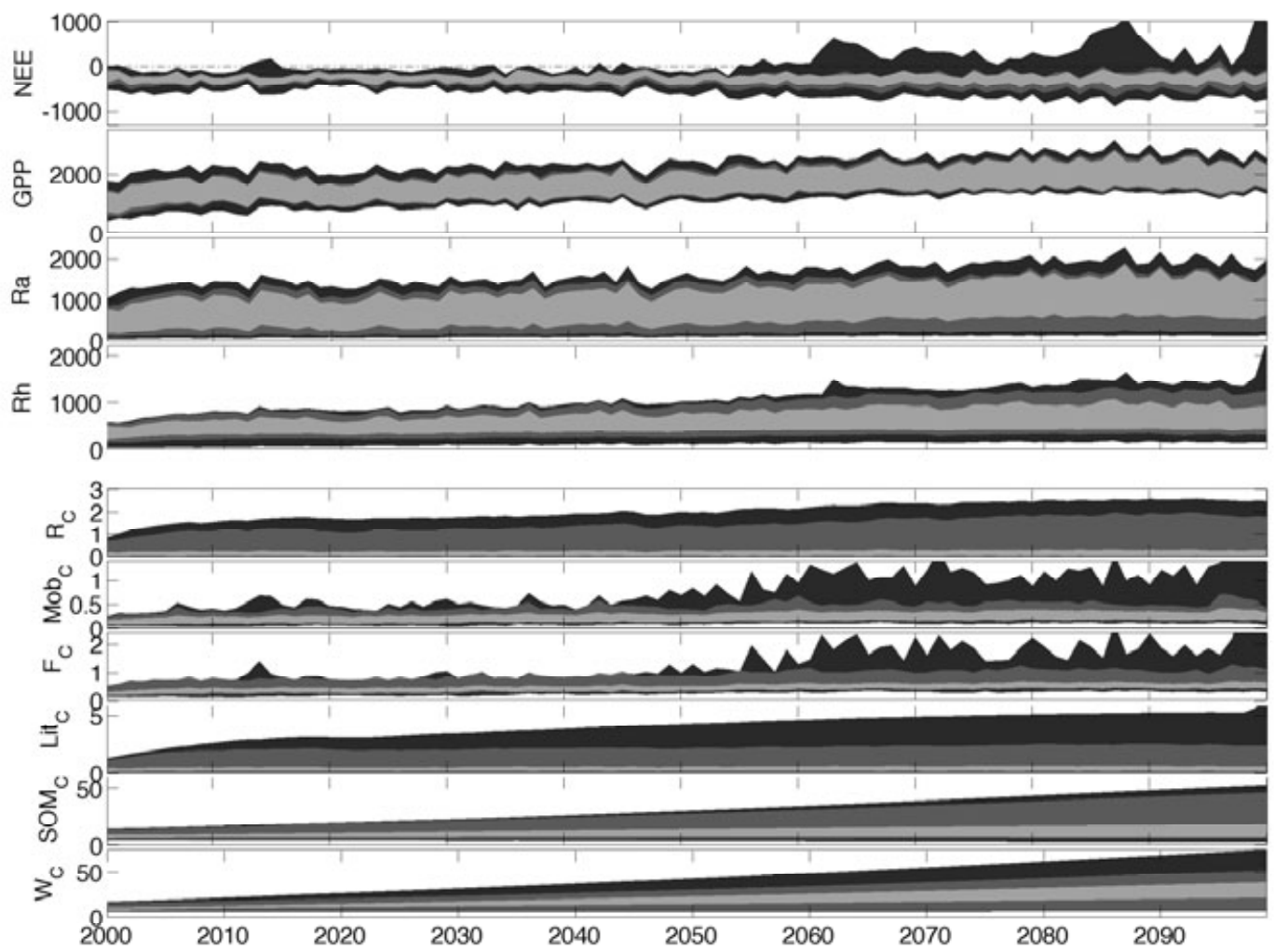

